\title{
Input and Output Inventories in General Equilibrium*
}

\author{
Matteo Iacoviello ${ }^{\dagger}$ \\ Boston College
}

\author{
Fabio Schiantarelli ${ }^{\ddagger}$ \\ Boston College and IZA
}

Scott Schuh ${ }^{\S}$

Federal Reserve Bank of Boston

October 23, 2009

\begin{abstract}
We build and estimate a two-sector (goods and services) dynamic stochastic general equilibrium model with two types of inventories: materials (input) inventories facilitate the production of finished goods, while finished goods (output) inventories yield utility services. The model is estimated using Bayesian methods. The estimated model replicates the volatility and cyclicality of inventory investment and inventory-to-target ratios. Although inventories are an important element of the model's propagation mechanism, shocks to inventory efficiency or management are not an important source of business cycles. When the model is estimated over two subperiods (pre and post 1984), changes in the volatility of inventory shocks or in structural parameters associated with inventories, such as the input inventory to output ratio, play a small role in reducing the volatility of output.

Keywords: Inventories, Business Cycles, Output Volatility, Bayesian Estimation, Great Moderation

JEL : E22, E32, E37

\footnotetext{
${ }^{*}$ We thank David DeRemer and Massimo Giovannini for invaluable research assistance and very useful discussions. We also thank Martin Eichenbaum, Fabià Gumbau-Brisa, Andreas Hornstein, Michel Juillard, Michael Kumhof, Lou Maccini, Julio Rotemberg, Paul Willen, and various seminar participants for very useful suggestions. And we thank Elizabeth Murry and Tyler Williams for expert editorial assistance. The views expressed in this paper are those of the authors only, and do not necessarily represent the views of the Federal Reserve Bank of Boston or the Federal Reserve System. A technical appendix containing additional details on the model and the data is available at the following webpage: http://www2.bc.edu/ iacoviel/research.htm.

${ }^{\dagger}$ Matteo Iacoviello, Boston College, Department of Economics, 140 Commonwealth Avenue, Chestnut Hill, MA 02467. Tel: (617) 552-3689. Fax: (617) 552-2308. Email: iacoviel@bc.edu.

${ }^{\ddagger}$ Fabio Schiantarelli, Boston College, Department of Economics, 140 Commonwealth Avenue, Chestnut Hill, MA 02467. Tel: (617) 552-4512. Fax: (617) 552-2308. Email: schianta@bc.edu.

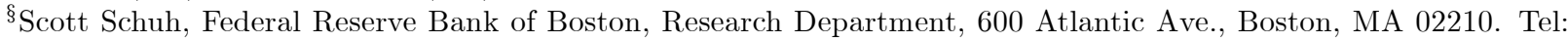
(617) 973-3941. Fax: (617) 619-7541. Email: scott.schuh@bos.frb.org.
} 


\section{Introduction}

Macroeconomists recognize that inventories play an important role in business cycle fluctuations, but constructing macroeconomic models that explain this role successfully has been an elusive task. ${ }^{1}$ Early Real Business Cycle (RBC) models, such as Kydland and Prescott (1982), treated inventories as a factor of production. However, Christiano (1988) showed that RBC models with aggregate inventories cannot explain the volatility and procyclicality of inventory investment without including a more complex information structure and restrictions on the timing of agents' decisions. Moreover, Christiano and Fitzgerald (1989) concluded, "the study of aggregate phenomena can safely abstract from inventory speculation." Nevertheless, the recent empirical literature continues to affirm the conventional view of inventories as propagating business cycle fluctuations. For example, McConnell and Perez-Quiros (2000), among others, argue that structural changes in inventory behavior are an important reason for the decline in the volatility of U.S. GDP since the early 1980s. ${ }^{2}$

We re-examine the role of inventories in business cycle fluctuations by developing and estimating a dynamic stochastic general equilibrium (DSGE) model rich enough to explain essential elements of inventory behavior. To confront the data, the model requires four extensions over existing models with inventories: 1) two sectors, differentiated by whether they hold inventories; 2) a disaggregation of inventories into two distinct types, input and output inventories; 3) several modern DSGE features, which have been shown to be necessary to fit the data; and 4) multiple shocks, which provide a diverse array of economically interpretable sources of stochastic variation. Because these extensions increase the complexity of the model, we abstract from other potentially important features — variable markups, nominal rigidities, intermediate goods with input-output relationships, and nonconvexities — that others have incorporated in equilibrium models of inventory behavior. ${ }^{3}$

Studying inventories in an equilibrium framework motivates a natural sectoral decomposition. Because inventories are goods mostly held by the firms that produce goods, our model contains a goods-producing sector that holds inventories and a service-producing sector that does not hold inventories. This inventory-based sector decomposition yields a broader goods sector than in prior studies that distinguished goods from services because the model includes industries that distribute goods (wholesale and retail trade plus utilities). ${ }^{4}$

\footnotetext{
${ }^{1}$ See Blinder and Maccini (1991) and Ramey and West (1999) for surveys. Ramey (1989) and Humphreys, Maccini, and Schuh (2001) study the importance of inventory investment in the decline of GDP during recessions.

${ }^{2}$ See also Blanchard and Simon (2001); Kahn, McConnell and Perez-Quiros (2002); Irvine and Schuh (2005a), and Herrera and Pesavento (2005).

${ }^{3}$ Papers that incorporate variable markups and/or sticky prices include Bils and Kahn (2000), Hornstein and Sarte (2001), Boileau and Letendre (2004), Coen-Pirani (2004), Jung and Yun (2006), and Chang, Hornstein, and Sarte (2006). General equilibrium models with intermediate goods and input-output relationships include Huang and Liu (2001) and Wen (2005a). Models with nonconvexities include Fisher and Hornstein (2000) and Khan and Thomas (2007), which incorporate (S,s) policies for retail inventories and intermediate goods inventories respectively.

${ }^{4}$ Marquis and Trehan (2005a) define goods as manufacturing firms, while Lee and Wolpin (2006) use the NIPA definition (agriculture, mining, construction, and manufacturing). For multi-sector consumption/investment models, see Kimball (1994); Greenwood, Hercowitz, and Krusell (2000); Whelan (2003); and Marquis and Trehan (2005b).
} 
Our model disaggregates inventories into input (materials and work-in-progress) and output (finished goods) stocks, as suggested by the stage-of-fabrication approach employed in Humphreys, Maccini and Schuh (2001). ${ }^{5}$ Wen (2005a) offers an alternative, theoretical analysis of input and output inventories in an equilibrium model. An advantage of these studies is that they incorporate the interaction between firms in a supply-chain, which we do not.

Our estimated model motivates holdings of the two inventory stocks differently. As in earlier DSGE models, such as Kydland and Prescott (1982) and Christiano (1988), input inventories enter as a factor in the production of value added, but only in the goods-producing sector. Holding input inventories is assumed to facilitate production by minimizing resource costs involved in procuring input materials, guarding against stockouts, and allowing for batch production.

Output inventories pose a different specification challenge. Most, but not all, of the inventory literature deals with partial-equilibrium analyses of the inventory-holding problem. Typically, a firm is assumed either to hold output inventories to avoid lost sales or stockouts (Kahn 1987) or to "facilitate" sales (Bils and Kahn 2000). Fisher and Hornstein (2000), instead, study the aggregate implications of output inventories decisions in a dynamic general equilibrium model with fixed ordering costs that generate (S,s) policies. Like Kahn, McConnell and Perez-Quiros (2002), we will take the shortcut of assuming that output inventories provide a convenience yield to the consumer and enter the consumers' utility function directly. The convenience yield may reflect the reduction in shopping cost associated, for instance, with less frequent stockouts and with the provision of variety or of other consumer benefits associated with the underlying retailing services. Indeed, under some simplifying assumptions, we can show that the model with output inventories in the utility function is equivalent to a model in which inventories appear in the budget constraint because they affect shopping costs, but do not enter the utility function. ${ }^{6}$ We are fully aware that our modeling choices for both input and output inventories are shortcuts taken in order to obtain a relatively simple estimable model. The judgement whether they are useful ones will partly depend upon the ability of our model to explain the movement of inventories over the business cycle.

Empirically, the data strongly suggest disaggregating aggregate inventories. We define output inventories $(F)$ as stocks held by retailers for final sale; all other stocks are input inventories $(M)$. By these definitions, input inventories empirically are more volatile and procyclical than output inventories. Perhaps more importantly, as implied by the model, the ratios of each inventory type to its steady-state target exhibit very different cyclical behavior. Relative to output of goods, input inventories $\left(M / Y_{g}\right)$ are very countercyclical. However, we find that relative to the consumption of goods, output inventories $\left(F / C_{g}\right)$ are mildly procyclical.

Our setup also includes several important features now standard in estimated DSGE models, such

\footnotetext{
${ }^{5}$ The importance of stage-of-fabrication inventories dates back to Lovell (1961) and Feldstein and Auerbach (1976). More recent models include Husted and Kollintzas (1987), Bivin (1988, 1993), Ramey (1989), and Rossana (1990). Cooper and Haltiwanger (1990) and Maccini and Pagan (2007) examine the linkages between firms created through inventories playing different input and output roles in production.

${ }^{6}$ The argument mimics the one proposed by Feenstra (1986) to justify the inclusion of money in the utility function.
} 
as adjustment costs on all capital stocks (including inventories) and variable utilization of capital. We also allow for nonzero inventory depreciation (or, equivalently, an inventory holding cost that is proportional to the total stock). ${ }^{7}$ This is a relatively novel feature in the inventory literature, except in models of inventories with highly perishable goods (Pindyck 1994). We allow nonzero depreciation because it is theoretically plausible and essential to fit the data. The model incorporates six shocks. We include two (correlated) sector-specific technology shocks and one demand-type shock to the discount rate. A fourth shock captures shifts in preferences between goods and services. Lastly, we introduce two inventory-specific shocks that create roles for unobserved changes in inventory technologies or preferences to influence the model.

We estimate the model using Bayesian likelihood methods. The estimated model fits the data well. Parameter estimates are consistent with the theory and are relatively precise. The estimated model replicates the volatility and procyclicality of inventory investment, and the qualitative differences in the observed cyclicality of the two inventory-target ratios. In particular, the model captures the countercyclicality of the input inventory ratio and the relatively acyclicality of the output inventory ratio. We also find that inventory shocks do explain some of the variation in investment and consumption, but little of the variation in aggregate output. Altogether, the results are consistent with the conventional view that inventories are an important part of the propagation mechanism, but in and of themselves are not an important source of macroeconomic fluctuations.

Our model and findings are related to Khan and Thomas (2007), who find that a calibrated equilibrium model with fixed delivery costs and driven by a single technology shock is successful in reproducing the cyclical properties exhibited by total inventories. We also match the cyclical properties of inventories, but our model distinguishes inventories by stage of fabrication and emphasizes the different cyclical properties of input and output inventories. The multiplicity of shocks in our model, the inclusion of a services sector (that does not hold inventories), and our use of Bayesian estimation (rather than calibration) constitute other important differences.

The econometric results shed light on inventory behavior over the business cycle. As in Christiano (1988), we find that the elasticity of substitution between input inventories and fixed capital in the production function is much smaller than unity. In contrast, the elasticity of substitution between consumption and output inventories in the utility function is closer to unity. Adjustment costs on fixed capital are large, while adjustment costs on inventory stocks are small and relatively insignificant. However, estimated depreciation rates for inventories, which might also reflect holding costs, are sizeable. Nonzero depreciation rates for inventories, together with fixed capital adjustment costs, are crucial in explaining the absolute and relative volatility of inventory investment and their role in the propagation mechanism.

Finally, we provide the first data-consistent, structural decomposition of the Great Moderation using an estimated DSGE model with independent roles for input and output inventories. By estimating the model over the sub-periods 1960-1983 and 1984-2007, we account for the notable changes

\footnotetext{
${ }^{7}$ Inventory carrying costs have however a long history in the operations management literature. See for instance the book by Stock and Lambert (2001).
} 
in the steady-state values of the inventory-to-target ratios and for the relatively greater importance of the service sector since 1984. We find that most of the decline in aggregate output volatility is attributable to the lower volatility of shocks, which occurred primarily in the goods-sector technology shock. ${ }^{8}$ The volatility of the input-inventory technology shock also declined, but this decline only accounts for a very small reduction in the volatility of aggregate output or goods output. We also find that structural changes in the parameters account for a smaller fraction of the reduction in aggregate output volatility. The reduced ratio of input inventories to goods output observed in the data is associated with a decrease in goods-sector output and GDP volatility, but the size of the decrease is small. ${ }^{9}$

\section{The Model}

\subsection{Motivating Inventories}

To motivate why input inventories (materials for short) are held, we follow the literature that treats them as a factor of production alongside labor and fixed capital, following a tradition going back to Kydland and Prescott (1982), Christiano (1988) and Ramey (1989). ${ }^{10}$ This approach assumes that the stock of inventories facilitates production - over and above their usage - by minimizing the cost of procuring input materials, by guarding against stockouts that would reduce productivity, and by allowing batch production. ${ }^{11}$ In the Kydland and Prescott and Christiano's general equilibrium models, the production function should be interpreted as a value added (gross output minus materials used) production function. As a factor aiding the production of value added, one can think of inventory stocks as a type of capital, which are characterized by adjustment and holding costs and subject to physical depreciation. ${ }^{12}$ In Section 6 , we also consider a version of the model in which we explicitly model the usage of materials and abstract from their convenience yield.

In modeling output inventories, we follow Kahn, McConnell and Perez-Quiros (2002) who assume that output inventories provide convenience services to the consumer and include them directly in the

\footnotetext{
${ }^{8}$ This result is consistent with other aggregate analyses of the Great Moderation. See the VAR-based analyses of Blanchard and Simon (2001); Stock and Watson (2003); and Ahmed, Levin, and Wilson (2004). See also Khan and Thomas (2007) and Maccini and Pagan (2007) for analyses based on structural models with inventories. Arias, Hansen, and Ohanian (2006) use a calibrated RBC model without inventories, and Leduc and Sill (2006) use an equilibrium model to assess the quantitative importance of monetary policy.

${ }^{9}$ Ramey and Vine (2006), studying the automobile industry, also do not find much evidence of structural change related to inventories. They emphasize structural change in the persistence of exogenous sales and, to a much lesser extent, in the costs of adjusting employment.

${ }^{10}$ See also Feroli (2002).

${ }^{11}$ Humphreys, Maccini, and Schuh (2001) and Maccini and Pagan (2007) argue that it is important to model the delivery and usage of input materials in gross production together with the holding of input inventories. However, absent input-output (supply-chain) relationships among firms, a representative-firm approach cannot admit deliveries of raw materials produced by an upstream supplier.

${ }^{12}$ If holding costs are proportional to the stock, then the inventory depreciation rate will include both physical wastage and the resource cost of holding inventories.
} 
utility function. The idea we are trying to capture is that a large stock of wine bottles at a local wine store increases utility beyond that derived from actually consuming the wine. The convenience yield may reflect the reduction in shopping cost associated, for instance, with less frequent stockouts and with the provision of variety or of other consumer benefits associated with the underlying retailing services. Indeed, under some simplifying assumptions, we can show that the model with output inventories in the utility function is equivalent to a model in which inventories appear in the budget constraint because they affect shopping costs, but do not enter the utility function. Feenstra (1986) proves the equivalence, under some (mild) conditions, between including consumption and money in the utility function; and including only consumption, but with liquidity/shopping costs - increasing in consumption and decreasing in money balances - appearing in the budget constraint. Feenstra's result suggests that our model with output inventories in the utility function, could be reinterpreted as a model having only consumption in the utility function, but having shopping costs in the budget constraint that are decreasing in output inventories. When the utility function is additively separable in consumption of goods and output inventories, on the one hand, and consumption of services, on the other, we can derive analytically the form of the shopping cost function. We discuss all this more fully in Section 6.

Our representative agent, perfectly competitive approach to output inventories abstracts from the decentralized problem of inventory holding by retailers (or by final good producers) that is common in partial-equilibrium analyses of inventories. To address this issue properly, one should model explicitly the relationship between individual consumers and retailers (or final good producers) in an imperfectly competitive setting. We leave this important task for future research in the context of a model that also allows for input-output (supply-chain) relationships, which are equally important to the decentralized problem. We also avoid modeling stockouts of output or input inventories explicitly and abstract from the presence of fixed ordering costs. We are aware that our modeling choices for both input and output inventories are shortcuts taken in order to obtain a relatively simple estimable model. The judgement whether they are useful ones will partly depend upon the ability of our model to explain the movement of inventories over the business cycle.

\subsection{Preferences}

The household chooses consumption of goods $C_{g}$, services $C_{s}$, output inventories $F$, and hours in the goods sector $L_{g}$ and services sector $L_{s}$ to maximize the following objective function: ${ }^{13}$

$$
E_{0} \sum_{t=0}^{\infty} \beta^{t}\left(\varepsilon_{\beta t}\left(\log \left(\gamma \varepsilon_{\gamma t} X_{t}^{-\phi}+\left(1-\gamma \varepsilon_{\gamma t}\right) C_{s t}^{-\phi}\right)^{-1 / \phi}-\tau\left(L_{g t}+L_{s t}\right)\right)\right),
$$

where $X_{t}$ is a CES bundle of goods and output inventories, and is defined as

$$
X_{t}=\left(\alpha \varepsilon_{F t} C_{g t}^{-\mu}+\left(1-\alpha \varepsilon_{F t}\right) F_{t-1}^{-\mu}\right)^{-1 / \mu}
$$

\footnotetext{
${ }^{13}$ To keep the model manageable, we do not distinguish within $C_{g}$ between durables and nondurables. On this see, for instance, Wen (2005b)
} 
where

$$
0<\gamma<1,0<\alpha<1 \text { and } \mu \geq-1 .
$$

In this formulation, $1+\mu$ is the inverse elasticity of substitution between the consumption of final goods and output inventories. Similarly, $1+\phi$ is the inverse elasticity of substitution between services and the bundle of goods (consumption-output inventories). Utility is linear in leisure, following Hansen (1985) and Rogerson (1988), which both assume that the economy is populated by a large number of identical households that agree on an efficient contract that allocates individuals either to full-time work or to zero hours.

We allow for three shocks to impact the intertemporal and intratemporal margins of the household. The shock $\varepsilon_{\beta t}$ affects preferences for goods, services, and leisure today versus tomorrow. The shock $\varepsilon_{\gamma t}$ affects the relative preference between goods and services. ${ }^{14}$ Finally, the shock $\varepsilon_{F t}$ affects the preference between the consumption of goods and output inventories: this shock is meant to capture the reduced-form impact on utility of temporary movements in the "technology" to produce output inventories occurring in the storage of physical goods. Low-frequency evolution in the storage and retailing technology (such as the emergence of megastores like Walmart, Internet shopping, and other key retail developments, especially since the early 1980s) might also be reflected in changes in structural parameters such as $\alpha$ and $\mu$ or in the volatility of the inventory specific shock $\varepsilon_{F t}$. Changes in $\alpha$ and $\mu$ will affect the ratio between output inventories and consumption. It is difficult to explicitly model these trends, but, at least, we will allow for discrete changes in the parameters by estimating the model separately for different subperiods (pre and post 1984).

\subsection{Technology}

Following Christiano (1988), value added in the goods sector is a Cobb-Douglas function in labor $L_{g t}$, and a CES aggregate of services from fixed capital and input inventories,

$$
Y_{g t}=\left(A_{g t} L_{g t}\right)^{1-\theta_{g}}\left(\sigma\left(z_{g t} K_{g t-1}\right)^{-\nu}+(1-\sigma)\left(\varepsilon_{M t} M_{t-1}\right)^{-\nu}\right)^{-\theta_{g} / \nu}
$$

where

$$
0<\sigma<1 \text { and } \nu \geq-1 .
$$

In equation (2.2), $K_{g t-1}$ is the end-of-period $t-1$ capital in the goods sector (plant, equipment, and structures), $z_{g t}$ is the time-varying utilization rate of $K_{g t-1}$, and $M_{t-1}$ is the end-of-period $t-1$ stock of input inventories. Here, $1+\nu$ measures the inverse elasticity of substitution between fixed capital and input inventories. If $\nu>0$, then fixed capital and input inventories will be defined here as complements; if $-1 \leq \nu \leq 0$ then input inventories and capital are substitutes.

The production function above does not explicitly feature the usage of materials as one of its arguments. Equation (2.2) describes a value added (gross output minus materials used) production

\footnotetext{
${ }^{14}$ For the model to admit a solution, a necessary condition is that $\gamma \varepsilon_{\gamma t}$ never exceeds unity for each possible realization of $\varepsilon_{\gamma t}$. Even though we assume that $\log \varepsilon_{\gamma t}$ has an unbounded support, empirically its standard deviation turns out to be rather small, so that this condition is always satisfied in practice.
} 
function, once materials used have been maximized out. So long as materials can be produced from gross output using a one-for-one technology, our model generates the same optimality conditions for primary inputs as a model that treats materials used as an additional factor of production in the production function of gross output. ${ }^{15}$

We allow for two disturbances in the goods sector technology: $A_{g t}$ is a technology shock, while $\varepsilon_{M t}$ is a shock that affects the productive efficiency of input inventories, so that $\varepsilon_{M t} M_{t-1}$ is input inventories in efficiency units. $\varepsilon_{M t}$ captures, in a reduced-form way, the impact on production efficiency of changes in the input inventory technology. The (low frequency) evolution over time of new methods of inventory management like just-in-time production or flexible manufacturing system, which are characterized by elaborate supply and distribution chains, may be reflected in changes in the volatility of $\varepsilon_{M t}$, in the weight of input inventories in the CES aggregate, $1-\sigma$, and in the parameter governing the elasticity of substitution, $\nu$, or, more generally, in the ratio between the stock of input inventories and goods output. ${ }^{16}$

Production in the services sector is modeled by a Cobb-Douglas production function only for labor $L_{s t}$ and capital services:

$$
Y_{s t}=\left(A_{s t} L_{s t}\right)^{1-\theta_{s}}\left(z_{s t} K_{s t-1}\right)^{\theta_{s}}
$$

where $K_{s t-1}$ is the end-of-period $t-1$ capital in the service sector and $z_{s t}$ is the time-varying utilization rate of $K_{s t-1}$. The empirical fact that service-producing firms do not hold inventories motivates our model's different specification of the services-production technology. We also allow for one general technology disturbance, $A_{s t}$, in the services sector.

\subsection{Resource Constraints}

Output from the goods sector provides consumption goods, new fixed investment in both sectors, and investment in output and input inventories. Output from the services sector provides services to the consumer. The resource constraints for the goods and service sectors are, respectively,

$$
\begin{aligned}
& Y_{g t}=C_{g t}+K_{g t}-\left(1-\delta_{K g}\left(z_{g t}\right)\right) K_{g t-1}+K_{s t}-\left(1-\delta_{K s}\left(z_{s t}\right)\right) K_{s t-1}+F_{t}-\left(1-\delta_{F}\right) F_{t-1} \\
& +M_{t}-\left(1-\delta_{M}\right) M_{t-1}+\xi_{K g}\left(K_{g t}, K_{g t-1}\right)+\xi_{K s}\left(K_{s t}, K_{s t-1}\right)+\xi_{F}\left(F_{t}, F_{t-1}\right)+\xi_{M}\left(M_{t}, M_{t-1}\right)
\end{aligned}
$$

and

$$
Y_{s t}=C_{s t}
$$

The capital depreciation rates in both sectors, $\delta_{K g}\left(z_{g t}\right)$ and $\delta_{K s}\left(z_{g t}\right)$, are increasing functions of the respective utilization rates. The inventory depreciation rates, $\delta_{F}$ and $\delta_{M}$, are fixed and possibly

\footnotetext{
${ }^{15}$ See Rotemberg and Woodford (1995) for a discussion of this issue.

${ }^{16}$ Irvine and Schuh (2005a) offer evidence that such supply-chain management may have changed. Information and computing technology may also play an important and related role in these new inventory management techniques, as argued by Kahn, McConnell, and Perez-Quiros (2002).
} 
capture inventory holding costs as well. Adjustment costs (denoted by $\xi$ ) are quadratic and given by the expression:

$$
\xi_{\Xi t}=\frac{\psi_{\Xi}}{2 \delta_{\Xi}}\left(\frac{\Xi_{t}-\Xi_{t-1}}{\Xi_{t-1}}\right)^{2} \Xi_{t-1}
$$

for $\Xi_{t}=\left(K_{g t}, K_{s t}, M_{t}, F_{t}\right)$. It is straightforward to show, log-linearizing around the steady state, that the elasticity of capital (investment) with respect to its shadow price is $\delta_{\Xi} / \psi_{\Xi}\left(1 / \psi_{\Xi}\right)$. For the utilization function, we choose a parameterization such that the marginal cost of utilization equals the marginal product of capital in steady state. ${ }^{17}$ The time $t$ depreciation rate of $K_{i t}$, defined as $\delta_{K i t}($ with $i=g, s)$, is given by

$$
\delta_{K i t}=\delta_{K i}+b_{K i} \zeta_{K i} z_{K i t}^{2} / 2+b_{K i}\left(1-\zeta_{K i}\right) z_{K i t}+b_{K i}\left(\zeta_{K i} / 2-1\right)
$$

The parameter $\zeta_{K i}>0$ determines the curvature of the capital-utilization function, where $b_{K i}=$ $1 / \beta-\left(1-\delta_{K i}\right)$ is a normalization that guarantees that steady-state utilization is unity.

\subsection{Shocks}

The shocks $A_{g t}, \varepsilon_{\beta t}, \varepsilon_{F t}, \varepsilon_{\gamma t}, \varepsilon_{M t}$ and $A_{s t}$, follow $\mathrm{AR}(1)$ stationary processes in logs:

$$
\begin{gathered}
\ln \left(A_{g t}\right)=\rho_{g} \ln \left(A_{g t-1}\right)+\left(1-\rho_{g}^{2}\right)^{1 / 2} u_{g t} \\
\ln \left(\varepsilon_{\beta t}\right)=\rho_{\beta} \ln \left(\varepsilon_{\beta t-1}\right)+\left(1-\rho_{\beta}^{2}\right)^{1 / 2} u_{\beta t} \\
\ln \left(\varepsilon_{F t}\right)=\rho_{F} \ln \left(\varepsilon_{F t-1}\right)+\left(1-\rho_{F}^{2}\right)^{1 / 2} u_{F t} \\
\ln \left(\varepsilon_{\gamma t}\right)=\rho_{\gamma} \ln \left(\varepsilon_{\gamma t-1}\right)+\left(1-\rho_{\gamma}^{2}\right)^{1 / 2} u_{\gamma t} \\
\ln \left(\varepsilon_{M t}\right)=\rho_{M} \ln \left(\varepsilon_{M t-1}\right)+\left(1-\rho_{M}^{2}\right)^{1 / 2} u_{M t} \\
\ln \left(A_{s t}\right)=\rho_{s} \ln \left(A_{s t-1}\right)+\left(1-\rho_{s}^{2}\right)^{1 / 2} u_{s t} .
\end{gathered}
$$

The innovations $u_{g t}, u_{\beta t}, u_{F t}, u_{\gamma t}, u_{M t}$, and $u_{s t}$ are serially uncorrelated with zero means and standard deviations given by $\sigma_{g}, \sigma_{\beta}, \sigma_{F}, \sigma_{\gamma}, \sigma_{M}$, and $\sigma_{s}$. In addition, we allow for correlation between the two technology innovations, $u_{g t}$ and $u_{s t}$.

\subsection{Optimality Conditions and Steady State}

Because the two welfare theorems apply, we solve the model as a planner's problem. The first-order conditions are standard and reported in Appendix A, along with a full characterization of the steady state. The model's optimality conditions, together with the market-clearing conditions and the laws of motion for the shocks, can be used to obtain a linear approximation around the steady state for the decision rules of the model variables, given the initial conditions and the realizations of the shocks. Given the model's structural parameters, the solution takes the form of a state-space econometric

\footnotetext{
${ }^{17}$ This way, steady-state depreciation is independent of the curvature of the function. See Christiano (2004).
} 
model that links the behavior of the endogenous variables to a vector of partially unobservable state variables that includes the six autoregressive shocks.

In our econometric application, we use observed deviations from the steady state of six variables, namely, the output of goods and services, the stock of input inventories and output inventories, the relative price of goods, and total fixed investment to estimate the model's parameters and the properties of the shocks. We will also require that the estimated parameters match the steady-state ratios of the model (proxied by their average values). Before describing the estimation procedure (Section 4), Section 3 maps the model variables into their data counterparts.

\subsection{Inventory Management Techniques and Steady-State Ratios}

Two of the model's steady-state ratios are worth highlighting. The steady-state ratios of input inventories to goods output, $M / Y_{g}$, and output inventories to goods consumption, $F / C_{g}$, are:

$$
\begin{gathered}
M / Y_{g}=\frac{\theta_{g}(1-\sigma)}{1-\beta\left(1-\delta_{M}\right)} \frac{\beta}{(1-\sigma)+\sigma\left(\frac{\sigma}{1-\sigma} \frac{1-\beta\left(1-\delta_{M}\right)}{1-\beta\left(1-\delta_{K g}\right)}\right)^{-\frac{\nu}{1+\nu}}} ; \\
F / C_{g}=\left(\frac{\alpha}{1-\alpha} \frac{1-\beta\left(1-\delta_{F}\right)}{\beta}\right)^{-\frac{1}{1+\mu}} .
\end{gathered}
$$

These ratios are structural analogues of the reduced-form "inventory-target" ratios that have played a central role in the inventory literature, which has usually taken a partial equilibrium approach to modeling inventories. The literature has primarily focused on output inventories, $F$, and $C_{g}$ is normally represented as the "sales" of a firm(s) - hence the "inventory-sales" ratio or target.

Changes in inventory-target ratios figure prominently in analyses of the data and hypotheses about improvements in inventory management techniques, as explained in the next section. Here we simply highlight the ways such techniques might be manifested through the theoretical model. Because the model does not explicitly incorporate inventory management techniques, changes in such techniques mostly likely would appear as changes in the structural parameters that determine the inventory-target ratios.

The input inventory-target ratio, $M / Y_{g}$, depends on three production function parameters that might reflect the current state of inventory management $\left(\sigma, \nu, \theta_{g}\right)$, as well as two depreciation rates $\left(\delta_{M}, \delta_{K_{g}}\right)$. The ratio is increasing in the relative weight of inventories in the non-labor input to production $(1-\sigma)$ and in the non-labor share of inputs in production $\left(\theta_{g}\right)$. Thus, new production techniques that economize on inventories, such as changes in delivery lags or ordering procedures for material inputs, may contribute to a lower ratio. The target ratio is also likely to be increasing in the degree of complementarity between inventories and fixed capital $(\nu) .{ }^{18}$ Investment in new types of capital associated with inventory management techniques might reduce this complementarity.

\footnotetext{
${ }^{18}$ This will be true if the term in the larger parenthesis in the denominator is greater than one, which is almost certainly the case in practice since capital has a much larger weight in production.
} 
Finally, the ratio is decreasing in inventory depreciation, $\delta_{M}$, although this parameter is unlikely to be directly related to inventory management techniques.

The output inventory target-ratio, $F / C_{g}$, depends on two utility function parameters $(\alpha, \mu)$ and one depreciation rate $\left(\delta_{F}\right)$. The ratio is increasing in the relative weight of inventories in the goods aggregator $1-\alpha$. It is also increasing in the degree of complementarity between consumption and inventories $(\mu)$ when the term in parenthesis in equation (2.15) is greater than one - a result that holds in our baseline estimates. ${ }^{19}$

\section{Data}

\subsection{Sector and Inventory Definitions}

To obtain model-consistent data, we divide the economy into two sectors according to the inventoryholding behavior of their industries: 1) the "goods" sector, which holds inventories; and 2) the "services" sector, which does not hold inventories (at least none as measured by statistical agencies). ${ }^{20}$ The goods sector includes seven industries: agriculture, mining, utilities, construction, manufacturing, and wholesale and retail trade. All other private-sector industries are in the services sector. ${ }^{21}$

Table 1 depicts our sectoral classification, compares it with the National Income and Product Accounts (NIPA) classification, and reports output shares in 2000. The goods sector accounts for a larger share of output than the NIPA goods sector (35.9 percent versus 21.2 percent). Nevertheless, under our definition, the services sector accounts for about three-fifths of private output (59.1 percent versus 40.9 percent for private goods), which excludes government but include foreign trade. However, the private goods sector becomes even larger after adjusting for foreign trade and the leasing of capital, as explained in the next subsection.

Our goods sector is larger than the NIPA good sector (and larger than conventional wisdom would suggest) because it includes the utilities, wholesale trade, and retail trade industries - all of which hold measured inventories. Reclassification of these NIPA-based "services" (utilities and trade) as "goods" can be motivated by assuming that the "service" provided - distributing goods from their producers to the final destination (consumers or firms) - can be internalized in a model of a representative goods producer which makes and distributes goods. ${ }^{22}$ Nevertheless, separate

\footnotetext{
${ }^{19}$ The papers by Kimura and Shiotani (2009) and Maccini and Pagan (2007) interpret changes in inventory-target ratios as evidence of changes in inventory management techniques, and attempt to map these techniques into particular parameters of a linear-quadratic inventory model.

${ }^{20}$ Given our reliance on inventory holding as the defining characteristic of sectors, we could equally well label the sectors "inventory holding" and "non-inventory holding" but we opted for "goods" and "services" because this nomenclature is simpler and more traditional. Moreover, in this two-sector model we wish to emphasize the integration of industries that produce goods (e.g., manufacturing) and those that distribute goods (e.g., retail trade) in the production of goods.

${ }^{21}$ See Appendix B for details on data sources, variable definitions, and data construction.

${ }^{22}$ Note that reclassification of utilities as goods production is consistent with other energy production that is included in the goods sector. Petroleum refining is in manufacturing, part of the standard NIPA goods sector.
} 
treatment of the production and distribution of goods may be preferable in future research that incorporates multiple stages of processing in the goods sector.

NIPA inventories are classified as input $(M)$ or output $(F)$ stocks following the stage-of-fabrication perspective advanced by Humphreys, Maccini, and Schuh (2001). Generally speaking, most goods production follows an input-output structure in which the output of one industry becomes an input to the next industry situated along a supply or distribution chain - raw materials, then work-in-process, and finally finished goods. Table 2 depicts this inventory classification scheme by industry, along with inventory shares in 2000. Inventory-holding industries appear in approximate order according to their location in the stages of fabrication; industries tending to producing raw materials are listed first, and industries tending to producing finished goods listed last. ${ }^{23}$

Prior research focuses on stage-of-fabrication inventories only within manufacturing. However, manufacturing only accounts for 31 percent of all inventories, so a decision must be made on how to classify the remaining 69 percent. We define $F$ as retail inventories because they represent the most finished stage of goods in supply and distribution chains. By this definition, output inventories account for about one-fourth of all stocks (26.6 percent), hence input inventories account for the about three-fourths (73.4 percent).$^{24}$

Our empirical definition of $F$ yields a smaller role for output inventories in general equilibrium than they play within manufacturing. Within manufacturing, output (finished goods) inventories account for about 36 percent of all manufacturing inventories (11.1 percent out of 31.1 percent). In addition, our empirical definition of input inventories is heavily oriented toward work-in-process inventories (54.5 percent), whereas these types of inventories account for only about 29 percent of all manufacturing stocks (8.9 percent out of 31.1 percent). Thus, one should not necessarily expect the stylized facts for stage-of-fabrication inventories in our general equilibrium model to be the same as for stage-of-fabrication inventories in manufacturing.

\subsection{Data Construction}

We use NIPA data and identities to construct data for the econometric work. For simplicity, we suppress the notational details associated with chain-weighted aggregation in the equations below describing the data construction. ${ }^{25}$ The output and investment data are constructed as follows:

$$
Y_{g}^{\text {data }}=C_{g}+I_{g}+I_{s}+\Delta F+\Delta M
$$

\footnotetext{
${ }^{23}$ According to the U.S. Census of Construction, inventories in the construction industry are materials and do not include unsold finished buildings.

${ }^{24} \mathrm{~A}$ reasonable case can be made for output inventories to include manufacturing finished goods and perhaps wholesale inventories. However, no clear theoretical (or empirical) justification exists for any particular alternative classification. For instance, wholesale inventories include construction material supplies, and manufacturing-output inventories contain goods that do not enter the consumer's utility function. Moreover, each industry's inventory investment exhibits different cyclical and trend characteristics, and the correlation of inventory investment between industries is low.

${ }^{25}$ All real data are in chain-weighted 2000 dollars. When constructing the actual real chain-weighted data, we use the Tornquist index approximation to the Fisher ideal chain index as recommended by Whelan (2002).
} 


$$
\begin{gathered}
Y_{s}=C_{s} \\
I_{g}=\omega\left(I_{n}+N X\right) \\
I_{s}=(1-\omega)\left(I_{n}+N X\right)+I_{r}
\end{gathered}
$$

where $I_{n}$ is nonresidential fixed investment, $I_{r}$ is residential fixed investment, $N X$ is net exports, and $\omega$ is the share of capital installed in the goods sector; NIPA data on $C_{g}$ and $C_{s}$ are modified slightly to match the sectoral definitions of the model. In estimating the model we account for the fact that NIPA output does not include inventory depreciation, whereas model output does: we thus subtract inventory depreciation from model output of goods, $Y_{g}$, in order to obtain measured goods output, $Y_{g}^{\text {data }}$. GDP is the Tornqvist index of measured output in the two sectors.

All data represent value added ("output" for short) of the private economy, which excludes government spending. We include net exports as part of investment: "[N]et exports are viewed as representing additions to, or claims on, the domestic capital stock, depending on whether they are positive or negative." (Cooley and Prescott 1995, footnote 13). Another advantage of including net exports in our definition of output is that our sample includes a period in which the U.S. moved from being a net exporter (before 1984) to running a significant trade deficit (since 1984): omitting net exports from our definition of goods could significantly bias our assessment of the trends in the inventory-output ratios.

Because the model and NIPA sectoral definitions differ, the standard NIPA consumption, investment, and inventory data require three adjustments to obtain model-consistent variables. First, consumption of energy services (such as gas and electricity) is reclassified as consumption of goods (energy) produced by the utilities industry. Second, non-NIPA investment-by-industry data are used to obtain measures of investment (capital installed) in each sector, which is not available in the NIPA data. A substantial proportion of investment occurs in the "real estate, rental and leasing" industry, which is in the services sector, but much of this capital actually is leased back to the goods sector. Thus, a portion of real estate and leasing investment is reclassified as goods investment. And third, inventory data from two industrial classification schemes - the old SIC system and the newer NAICS system - are spliced to obtain consistent time-series data for the entire sample. Appendix B provides complete details of the data construction and adjustments.

\subsection{Output and Investment Data}

Figure 1 plots the raw data in real terms (normalized to 100 in 1960). As the figure illustrates, the series have grown at different real rates over the sample period. In particular, output in the services sector has grown faster than in the goods sector, and input inventories have grown much slower than output inventories, especially since the early 1980s. Figure 2 plots each variable in nominal terms as a share of total output. The ratios of total consumption-to-output and total investment-to-output are roughly constant, except for the slight downward trend in the investment-to-output ratio during the second half of the sample due to the decline in net exports. 
However, the nominal ratios in each sector are not roughly constant. ${ }^{26}$ The most noticeable sector-level trends are the opposing trends in consumption (an upward drift in the share of services consumption, from 30 percent to 50 percent, and a downward drift in the share of goods consumption of the reverse magnitude), and the different trends in inventory stocks (downward drift in the ratio of input inventories and upward drift in the ratio of output inventories). Similarly, the ratio of investment-to-output in goods is declining while that ratio in services is roughly constant. These changing shares of goods and services have been extensively discussed in the literature and reflect the slow reallocation of resources from manufacturing to services, a process often referred to as "structural change" and well documented at least since Kuznets (1957).

The sector-level trends in the data pose a challenge in terms of modeling choices. Standard onesector models of the business cycle rely on an important property of U.S. macroeconomic aggregates: the nominal shares of total consumption and investment in total GDP have been roughly constant over the post-world-war II period. The plain-vanilla one-sector model, indeed, features "balanced growth": output, consumption and investment all grow at about the same rate, and the decentralized equilibrium features constant relative prices across output, consumption and investment (Whelan, 2003). Extensions of the one-sector model to a multi-sector framework allow for balanced growth even if the real variables are growing at different rates over time, so long as preferences and technology satisfy specific functional forms. ${ }^{27}$ In these extensions, although there is no balanced growth in the traditional sense, it is possible to find a transformation of the model variables that will render them stationary. This transformation, loosely speaking, is admissible insofar as variables grow at different rates in real terms, but relative prices adjust in a way that expenditure shares remain constant. Hence a necessary condition for balanced growth both in one-sector and multi-sector models is that nominal ratios are approximately constant over time. ${ }^{28}$ Our framework, however, features a finer level of disaggregation than typical multi-sector models. In particular, it divides consumption into two categories (goods and services) and investment into three categories (business investment, input inventory investment, and output inventory investment). The discipline of a model obeying the balanced growth property would require the shares of Figure 2 to be stationary, but they are not. Jointly modeling of the trend and the cycle would be fascinating, but the data appear to reject balanced growth at the level of disaggregation that we propose in the model. Thus, we use standard filtering techniques to remove the trends from each variable prior to estimation.

\footnotetext{
${ }^{26}$ In real terms, the ratio of investment to output has trended upwards during the sample. However, the relative price of investment has fallen, so the nominal ratio of output to investment has remained approximately constant.

${ }^{27}$ Kongsamut, Rebelo and Xie (2001) and Gomme and Rupert (2007) discuss the restrictions on preferences and technology that are required for balanced growth in multisector models. These restrictions call for production functions and consumption aggregators to be Cobb-Douglas.

${ }^{28}$ In models with endogenous labor, an often stated condition for balanced growth is that hours are stationary. Strictly speaking, this is not necessary, so long as the real wage rate adjusts in a way that the ratio of total compensation (wage times hours) to consumption remains constant. For instance, see Chang, Doh and Schorfheide (2007).
} 


\subsection{Inventory Data and the Inventory Management Hypotheses}

Figure 3 (top panel) plots the inventory-target ratios of the model, $F / C_{g}$ and $M / Y_{g} \cdot{ }^{29}$ A striking fact is that input and output inventory-target ratios exhibit opposite trends over the full sample. The input inventory ratio $\left(M / Y_{g}\right)$ declined by about one-third (from about 1.5 to 1.0) and the output inventory ratio $\left(F / C_{g}\right)$ increased by 50 percent (from about 0.35 to 0.5 ). Because input inventories account for most of the inventory stock (73.4 percent, from Table 2), the aggregate inventory-target ratio $-M+F$ relative to either $Y_{g}$ or $C_{g}$ - declined.

A more detailed examination of these disparate trends is warranted. The prevailing view in the literature is that a decline in $(M+F) / Y_{g}$ and $M / Y_{g}$ likely resulted from improvements in inventory management and associated production techniques commonly referred to as "Just-inTime" production, "Flexible Manufacturing Systems", "Material Resources Planning," etc. However, the literature offers little or no explanation for a rising inventory-target ratio like $F / C_{g}$, perhaps because inventories in the retail industry are not examined much in the literature. Yet measurement of inventory-target ratios is crucial. Ramey and Vine (2004) rightly point out that the ratios should have a numerator (inventories) and denominator (target) that are measured for the same sectors of the economy: they show that the aggregate U.S. inventory-target ratio declines after the early 1980s when measured in nominal terms, but not in real terms, because: 1) the price of goods relative to services is declining; and 2) aggregate inventories are goods but aggregate sales are for goods and services. Ramey and Vine recommend using a target measure pertaining to the goods sector only (which our model does), and show that the downward trends of the nominal ratio disappears, casting some doubt on the better inventory management hypothesis.

However, Kahn and McConnell (2005) point out an additional mismatch in the Ramey-Vine adjusted ratio: it excludes farm inventories (part of the goods sector) from the numerator but not the denominator. The Ramey-Vine adjusted inventory-target ratio trends upward before 1980 and downward since, but has no trend over the full sample. Alternatively, Kahn and McConnell focus on the durable and non-durable goods sectors, in which they claim inventory management changes were concentrated, and show that the properly measured inventory-target ratio is flat prior to the 1980s and declining since - clearer evidence of a change in inventory technology. ${ }^{30}$ Our general equilibrium analysis is applied to the entire economy, so our input inventory-target measure includes farm inventories and exhibits trends similar to the narrower Kahn-McConnell measure. ${ }^{31}$

\footnotetext{
${ }^{29}$ Although $M / Y_{g}$ is consistent with traditional practice in the inventory literature, such as Lovell (1961) and Feldstein and Auerbach (1976), $F / C_{g}$ differs from the traditional inventory-to-sales ratio specified by microeconomic models of the firm. In the model, the "sales" measure most analogous to that used in the inventory literature is final goods sales, $S_{g}=C_{g}+I$. Empirically, however, the choice of the scale variable for inventories does not alter the qualitative properties of inventory-target ratios.

${ }^{30}$ Our real and nominal inventory-target ratios are similar (for both input and output inventories) because the inventory and target measures pertain to the same sectors of the economy and thus are not susceptible to changes in relative prices.

${ }^{31}$ Irvine (2005) shows that: (1) the aggregate inventory-target ratio declines since the early 1980 s due to shifts in the mix of sales toward durable goods industries, which have lower inventory-target ratios (presumably because of better
} 
Numerous authors argue that the downward trend break in the aggregate inventory-target ratio may be associated with changes in inventory management. McConnell and Perez-Quiros (2000) observe that the decline in GDP volatility is associated with the inventory-holding sector of the economy (our goods sector) and deduce that inventory management must have changed but do not link the change to the inventory-target ratio. Kahn, McConnell, and Perez-Quiros (2002), or KMP, show that the decline in the inventory-target ratio occurred almost exclusively in the durable goods portion of the goods sector and argue that it reflects increased investment in information technology (IT) capital, which allows firms to respond faster to changing demand conditions with lower inventory stocks. However, the KMP model derives an inventory-target ratio from the utility function only, which does not change as a result of inventory management changes, whereas the actual ratio in the data does decline. ${ }^{32}$

The KMP analysis does not distinguish between input and output inventories, but Figure 3 shows a decline in the inventory-target ratio for input inventories only. Looking at manufacturing data alone, one finds that the decline in the inventory-target ratio occurred for input inventories in manufacturing, especially durable goods manufacturing (e.g., Humphreys, Maccini, and Schuh 2001). In contrast, output inventories in manufacturing are roughly constant relative to their target. Not surprisingly, adoption of innovative new inventory management and production techniques occurred most extensively in the supply chains of durable goods manufacturers.

One potentially data-consistent explanation for a decline in the input inventory-target ratio of durable goods manufacturers, advanced by Davis and Kahn (2008), is a reduction in delivery times by materials suppliers for manufacturers. Faster delivery times by suppliers makes it possible for manufacturers, who order and stock materials (or works-in-process) as input inventories, to hold fewer input inventories relative to their sales. Modeling this feature requires a supply chain of at least two goods-producing firms (which our model does not have). Alternatively, holding fewer inventories relative to sales would be possible if the volatility of demand declined, as predicted by stockout avoidance models such as Kahn (1987). Because the decline in the input inventory-target ratio occurred at about the same time that GDP volatility declined - the "Great Moderation" - a connection between these two events is a natural hypothesis to evaluate.

Unlike input inventories, output (retail) inventories have been rising relative to their target $\left(F / C_{g}\right)$. Much less attention has been devoted to explaining this phenomenon and its implications for the aggregate economy. However, by separating inventories into input and output components, we highlight the need to understand the economic factors behind the trend increase in output inventories. The output inventory-target ratio leveled off in the 1990s, much later than the break for the input inventory-target ratio. This fact may reflect an effect of inventory management occur-

inventory management); (2) retail and wholesale inventories, relative to their respective industry sales, trend upward; (3) trend breaks appear in the inventory-target ratios of most industries but the breaks are not all downward, as evident in aggregate ratios.

${ }^{32}$ This model is designed primarily to explain a reduction in the volatility of output, especially relative to the volatility of sales, rather than a decline in the inventory-target ratio. 
ring later than for input inventories, but the evidence for this hypothesis is less clear and warrants much additional investigation. Finally, a rising output inventory-target ratio may be consistent with a love-for-variety story, in which firms are required to keep a larger, more diverse stock of finished goods to satisfy greater demand for variety coming from an increase in the number of types of goods produced.

\subsection{Cyclical Properties}

For all of the reasons described earlier about the complexity of the sectoral trends, and following the common procedure in the inventory literature, we detrended all data used in the econometric work with a conventional bandpass filter. ${ }^{33}$ By all measures, output in the goods sector is much more variable than output in the service sector. For our definition of the goods sector (first column of Table 1), output fluctuations in the goods sector account for 76 percent of the variance of aggregate output in real terms. By comparison, the growth rate of goods output in the narrower, more volatile NIPA definition of goods (second column of Table 1, not including the construction industry) accounts for 89 percent of the variance of real GDP growth, according to Irvine and Schuh (2005b). Our goods sector accounts for less of aggregate output variance because it includes relatively less volatile industries, such as wholesale and retail trade.

Moving to inventories, the middle panel of Figure 3 shows how inventory-target ratios exhibit markedly different cyclical properties. On average, the output-inventory ratio is roughly acyclical (the correlation with goods output is 0.10 ), as can be seen by the lack of consistent movement during recessions (shaded regions). Although the output-inventory ratio shot up during the 1973-75 recession, it has not done so during other recessions. In contrast, the input-inventory ratio is very countercyclical (the correlation with goods output is -0.89 ), as can be seen by its consistent increase during recessions. Thus, the existence of countercyclical inventory-target ratios for manufacturing output inventories, as emphasized by Bils and Kahn (2000), is not evident for all inventories. This result suggests that successful theories of aggregate inventory behavior must be comprehensive enough to explain heterogenous behavior among different types of stocks.

Another key fact, seen in the bottom panel of Figure 3, is that input-inventory investment is much more volatile than output-inventory investment (the ratio of variances is about 2), when both investment series are normalized by total output. This relative volatility is comparable to the analogous variance ratios observed within manufacturing (Blinder and Maccini 1991). However, the relative volatility of the two types of inventory investment has declined dramatically, from a ratio of 4.6 in the early sample (1960-1983) to a ratio of 2.5 since then. The volatility of input-inventory

\footnotetext{
${ }^{33} \mathrm{~A}$ trend is removed from the variables in logs, using the band-pass filter of Baxter and King (1999) that isolates frequencies between 3 and 32 quarters. Linear quadratic detrending and first-differencing are also common in the literature, but these techniques tend to yield similar cyclical properties in the detrended data. Wen (2005c) shows that the cyclical properties of detrended inventory investment are sensitive to the cyclical frequency. Business cycle frequencies like ours yield procyclical inventory investment, whereas higher frequencies (2-3 quarters) yield countercyclical inventory investment.
} 
investment fell while the volatility of output-inventory investment remained about constant. Both types of inventory investment are procyclical over the full sample, but input-inventory investment is more procyclical than output-inventory investment (the correlation with goods output is 0.62 for input inventories and 0.42 for output inventories). The procyclicality of output-inventory investment decreased from 0.44 in the early sample (1960-1983) to 0.25 since then, but the cyclical correlation of input-inventory investment has remained relatively stable.

In sum, the distinctly different cyclical properties of input- and output-inventory investment provide additional motivation for disaggregating inventories. Thus, theoretical models that allow different inventory-target adjustments and volatility across stocks are likely to have an advantage in explaining and understanding aggregate inventory behavior.

\section{Model Estimation}

\subsection{Overview}

We use observations on the following variables: (1) output from the goods sector; (2) output from the service sector; (3) the stock of input inventories; (4) the stock of output inventories; (5) total fixed investment; (6) the relative price of goods to services. We estimate the model for the full sample from 1960:1-2007:4. We also estimate the model for the two subperiods: 1960:1-1983:4 and 1984:1-2007:4. The breakpoint corresponds to point estimates of when the Great Moderation began, as indicated in McConnell and Perez-Quiros (2000).

We use Bayesian techniques to estimate the structural parameters. ${ }^{34}$ For given values of the parameters, the solution to our linearized model takes the form of a state-space econometric model, and the Kalman filter enables to evaluate the likelihood of the observable variables as follows:

$$
L\left(\left\{x_{t}\right\}_{t=1}^{T} \mid \Upsilon\right)
$$

where $\Upsilon$ is the vector collecting all the model parameters and $x_{t}$ is the vector of observable variables. We combine the information observed in the data with prior information on the model parameters to construct the posterior density function:

$$
p\left(\Upsilon \mid\left\{x_{t}\right\}_{t=1}^{T}\right) \propto L\left(\left\{x_{t}\right\}_{t=1}^{T} \mid \Upsilon\right) \Pi(\Upsilon)
$$

Specifically, we first calculate the posterior mode of the parameters using a numerical optimization procedure. Then we generate 250,000 draws from the posterior mode using the Metropolis-Hastings algorithm to obtain the posterior distribution. The mean of the posterior distribution is used to compute impulse response functions, variance decompositions, and moments of the estimated model.

\subsection{Prior Distributions}

We keep some parameters fixed during our estimation exercise. More specifically, we set the quarterly discount factor at 0.99 , implying an annual interest rate of 4 percent. We also calibrate the

\footnotetext{
${ }^{34}$ For the solution and the estimation of the model, we use the Dynare toolkit developed by Michel Juillard.
} 
depreciation rates for fixed capital, which we set at $\delta_{K g}=\delta_{K s}=0.02 .{ }^{35}$ Once these values are set, 29 remaining parameters need to be estimated. We partition these into three groups:

1. The autocorrelation parameters $\left(\rho_{g}, \rho_{\beta}, \rho_{F}, \rho_{\gamma}, \rho_{M}, \rho_{s}\right)$, standard deviations of the innovation disturbances $\left(\sigma_{g}, \sigma_{\beta}, \sigma_{F}, \sigma_{\gamma}, \sigma_{M}, \sigma_{s}\right)$, and the correlation between the innovations in the goods-sector technology and the services-sector technology $\left(\sigma_{g, s}\right)$.

2. The adjustment cost parameters $\left(\psi_{K g}, \psi_{K s}, \psi_{F}\right.$, and $\left.\psi_{M}\right)$, and the parameters characterizing the curvature of the utilization functions for fixed capital $\left(\zeta_{K g}, \zeta_{K s}\right)$.

3. The inventory depreciation rates $\left(\delta_{M}\right.$ and $\left.\delta_{F}\right)$, the elasticities of substitution $(\nu, \phi, \mu)$, the labor shares $\left(\theta_{g}, \theta_{s}\right)$, the weight of services in utility $(\gamma)$, the weight of input inventories in the CES capital aggregator $(\sigma)$, and the weight $(\alpha)$ on consumption in the goods-bundle aggregator. This third group of parameters affects not only the model's dynamics, but also the steadystate values of fixed capital and input- and output-inventory stocks relative to output, as well as the relative size of the service versus the goods sector. For our sample (and for the two subsamples), the average values of these ratios are reported in Table 3. One can show that, for each combination of $\delta_{M}, \delta_{F}, \nu, \phi, \mu$, it is possible to determine a unique set of values for $\theta_{g}, \theta_{s}, \gamma, \sigma$, and $\alpha$ that are consistent with these five ratios. ${ }^{36}$ Accordingly, in the estimation of the model, for each value of $\delta_{M}, \delta_{F}, \nu, \phi$ and $\mu$, we set $\theta_{g}, \theta_{s}, \gamma, \sigma$ and $\alpha$ to the values that match the ratios. ${ }^{37}$ Intuitively, we let the likelihood function use information on the behavior around the steady state of our observables to determine values for the depreciation rates, $\delta_{F}$ and $\delta_{M}$, and the elasticity of substitution in the CES aggregates in the production and utility functions, $\nu, \phi$, and $\mu$ (in addition to the autocorrelation, adjustment costs, and utilization function parameters). We then use the ratios reported in Table 3 to recover the remaining parameters. This procedure also enables us to account for the changes in the ratios over the sample period: when we estimate the model separately for the two subsamples, we use the average values of the relevant ratios in each period. ${ }^{38}$

\footnotetext{
${ }^{35}$ In the data, the service sector has a higher proportion of structures in its total capital stock than the goods sector does. Because structures generally have lower depreciation rates than equipment, we also estimated a model with a smaller depreciation rate of capital in the service sector, obtaining similar results.

${ }^{36}$ See Appendix A for additional details.

${ }^{37}$ Christiano (1988) follows the same strategy: in his model, which includes inventories in the production function, he chooses $\sigma$ (in our notation) to maximize the likelihood function and $\nu$ (our notation) to match the steady-state rental rate of inventories in the data.

${ }^{38}$ Essentially, what we are doing is to construct degenerate, non-independent priors for a set of parameters $\left(\theta_{g}, \theta_{s}, \gamma, \sigma, \alpha\right)$ with the goal of matching exactly five first moments of the data that are excluded from the likelihood function (that is, they are not used as part of our estimation exercise). A different way of putting it is that these parameters can be more easily identified from steady state relationships among the variables rather than from the dynamics of the data. Del Negro and Schorfheide (2008) provide and describe a more general approach for forming priors for steady-state related parameters that allows for the steady-state to be measured with error: we implicitly rule measurement error out here.
} 
Our prior distributions are summarized in the first three columns of Table 4. For the parameters measuring adjustment $\operatorname{costs} \psi$, we specify a beta prior over $\frac{\psi}{1+\psi}$, with mean equal to 0.5 : this value corresponds to a prior mean of unity for the elasticity of investment to its shadow price. For the curvature of the utilization function, we choose a beta prior over $\frac{\zeta}{1+\zeta}$ with mean equal to 0.5 . For the elasticity of substitution between services and the goods bundle, between consumption and output inventories, and between input inventories and capital, we select priors centered around two thirds. In other words, our prior goes slightly in favor of complementarity.

The existing literature and the NIPA offer little guidance in choosing the inventory depreciation rates, $\delta_{F}$ and $\delta_{M}$. An assumption in line with the procedures used in the NIPA would be that inventories do not depreciate. Yet inventories are subject to various forms of "shrinkage," such as obsolescence, perishability, wear and tear, and breakage, in addition to incurring holding costs, so that the depreciation parameter may well be larger than the rate set for fixed capital. For instance, on a quarterly basis, Ramey (1989) reports inventory holding and storage costs of 4 percent, while Khan and Thomas (2007) set these costs at 3 percent. We balance NIPA and other studies and choose a prior mean for the depreciation rates equal to 0.02 .

The autoregressive coefficients of the exogenous shocks have beta prior distributions, as in Smets and Wouters (2003), centered at 0.75. The standard deviations of the shocks are assigned a diffuse inverse gamma distribution prior. The correlation between $u_{g t}$ and $u_{s t}$ is assumed to be normal and is centered around 0.50. The choices of the mean of the prior distribution for the standard deviation of the technology and preference shocks are in the ballpark of the findings in the literature. ${ }^{39}$ Preliminary estimation attempts also suggested a higher standard deviation for the input inventory shock relative to the output inventory shock.

\section{Estimation results}

\subsection{Full sample}

Parameter Estimates. We begin by discussing the estimates for the entire sample. Table 4 reports the mean and the 5 th and 95 th percentiles of the posterior distribution of the parameters obtained through the Metropolis-Hastings algorithm. ${ }^{40}$

All shocks are estimated to be quite persistent, with the autoregressive parameters ranging from 0.86 to 0.94 . The standard deviation of the shocks ranges from $0.33 \%$ (for the output-inventory shock) to $10.34 \%$ (for the input-inventory shock): the quantitative relevance of each shock will be discussed below in the variance-decomposition exercise.

\footnotetext{
${ }^{39}$ See, for instance, Ireland (2004) and Smets and Wouters (2003).

${ }^{40}$ As is well known (see, for instance, Canova 2007), an important issue concerns the convergence of the simulated draws from the posterior distribution of the parameters. We fine tune our estimation algorithm in order to obtain acceptance rates between 30 and 40 percent, and we check for convergence using the cumulative sum of the draws statistics. Although convergence typically obtains within 50,000 iterations, we set the number of draws to 250,000 and calculate the statistics based on the last 75 percent of the draws.
} 
The elasticity of substitution between $M$ and $K$ (the inverse of $1+\nu$ ) equals 0.28 . The elasticity of substitution between $F$ and $C_{g}$ (the inverse of $1+\mu$ ) equals 0.77 , and is not significantly different from unity. Similarly, the elasticity of substitution between services and the CES aggregator for consumption of goods and output inventories (the inverse of $1+\phi$ ) is close to one.

Estimates of the inventory adjustment-cost parameters, $\psi_{F}$ and $\psi_{M}$, are close to zero, while the bigger values of $\psi_{K g}$ and $\psi_{K s}$ indicate larger adjustment costs for fixed capital. At the posterior mean, the estimated values imply an elasticity of investment to the user cost equal to 6 in the goods sector, and equal to 3.1 in the service sector. ${ }^{41}$ These different elasticities confirm that input inventories and fixed capital are indeed distinguished by having different degrees of adjustment costs.

Another important difference between inventories and fixed capital emerges from the estimated depreciation rates. The depreciation rate for $M$ is 2.2 percent, about the same as capital, but the depreciation rate for $F$ is 8.1 percent, much larger: as we will show below, the nonzero depreciation rates are a key feature of the model in generating large and positive responses of inventories to productivity shocks. Finally, estimates of the convexity of the utilization function suggest that the marginal cost of capital utilization (in terms of increased depreciation) is more sensitive to changes in the utilization rate in the service sector than in the good sector.

Impulse Responses and Variance Decompositions. Figure 4 presents the model impulse responses to the estimated shocks. In Table 6, we report asymptotic variance decompositions. Both in Figure 5 and in Table 6, we choose an orthogonalization scheme that orders the goods technology before the services technology shock. As a result, any variation in the responses due to the correlation between the goods and the services shock is attributed to the goods technology disturbance.

The first row plots the responses to a positive goods technology shock. ${ }^{42}$ This disturbance is fundamental in generating comovement of quantities in our model, and accounts for a large fraction of the fluctuations in economic activity. In response to the shock, consumption, business investment and both types of inventory investment all rise. The goods shock spills over to the service sector (over and above the effect caused by the correlation of the shocks) because it facilitates the production of fixed capital that is then used in the service sector. The goods technology shock also accounts for a non-negligible fraction of the fluctuations in both types of inventory investment - around 1112 percent of their asymptotic variance. The responses of output and input inventory investment are, as a proportion of the respective stocks, larger than the one for fixed investment, relative to the fixed capital stock. For instance, the impact response of input inventories relative to business investment is two-thirds as big, when both variables are scaled by goods output. However, since the stock of business capital is about ten times larger than the stock of input inventories, the response of

\footnotetext{
${ }^{41}$ One can interpret $\psi$ as the inverse elasticity of each type of investment to its shadow price. Our numbers are slightly higher than microeconometric findings based on estimates of investment equations (see Chirinko, 1993).

${ }^{42}$ To facilitate comparison across all investment categories, we scale the response of inventory investment and business investment by steady-state goods output (rather than by their own steady state values). This way, the vertical axis measures the percent growth contribution of each investment category to the response of goods output. Note that in the figures and in the tables the measure of $Y_{g}$ is net of inventory depreciation.
} 
input inventories is between six and seven times larger than that of business investment, when both variables are scaled by their own steady-state stock. This is not surprising, since fixed capital is more costly to adjust. In this sense, inventories are an important part of the propagation mechanism, even if inventory investment counts for a small fraction of average output.

The second row shows the responses to a discount factor shock: this shock moves consumption and investment in opposite directions, and creates negative comovement between the output of each sector. It also contributes to fluctuations of input inventories - about 20 percent of the total variance.

The third row shows responses to a shock that shifts preferences away from output inventories towards goods consumption. The mechanics of this disturbance have the classic implications of a demand shock. Consumption of goods increases; inventories of finished goods fall; following the increase in demand, with a modest lag, the output of the goods sector increases while output of the service sector is only marginally affected (because the estimated elasticity of substitution implies an approximate separability in utility between goods and services). This preference-based shock accounts for a large share (about 80 percent) of the variance in output-inventory investment.

The fourth row shows the response to a shock that shifts preferences away from services and towards goods. While this shock, which basically reflects shifts in the composition of demand, accounts only for a small fraction of GDP fluctuations, it accounts for a quarter of the variance of output in the service sector. It also accounts for about half of the total variance of sectoral hours, because the shock causes a reallocation of labor from one sector to the other.

The fifth row plots the response to a positive shock to the efficiency of input inventories. This shock captures a large fraction (about two-thirds) of the variance in input-inventory investment. More efficient management of input inventories reduces their usage, increases the demand for fixed capital, and raises consumption (immediately) and output (with a slight delay). The shock also accounts for around 10 percent of the variance of fixed investment.

The last row plots responses to a technology shock in the service sector. While it is obviously important in explaining output of services, the effects of the shock in this sector transmit only marginally to the rest of the economy, since the services sector does not produce capital. ${ }^{43}$

The literature has often looked at the cyclical properties of the inventory-target ratios, so Figure 5 reports the impulse responses of GDP and the inventory-target ratios to the four disturbances goods technology shock, discount factor shock, output-inventory shock, and input-inventory shock that cause most of the variation in GDP and inventories. Following the goods technology shock, the input-inventory target ratio is strongly countercyclical, as in the data. Input inventories rise, but, since business capital is costly to adjust, input inventories - which are complementary to business capital - do not rise enough, so that their ratio to GDP falls. The output inventory-target ratio is almost acyclical (as in the data), since the household prefers to maintain a relatively constant

\footnotetext{
${ }^{43}$ The logic of this result can be interpreted using an analogy to the consumption-technology neutrality result described in Kimball (1994). With separable preferences over goods and services (as implied by our estimated model), technology shocks that only affect the consumption-producing sector (in our model, the service sector) also have no impact on employment or capital accumulation.
} 
balance of output inventories to consumption. The second row plots the dynamics following the discount factor shock: since input inventories falls less than output, the input inventory to GDP ratio rises, again generating countercyclical behavior of the input inventory to target ratio. The third and fourth row plot the responses to the inventory-specific shocks. While these shocks are central to reproducing the volatility of inventory investment observed in the data, they mostly affect the inventory-target ratios through their effects on the numerators, without having large effects on output or consumption. In other words, inventory-specific shocks help fit the volatility of inventory investment, but they do not influence the cyclical properties of the inventory-target ratios, which are mostly driven by the aggregate productivity shocks.

We conclude this subsection with a note of caution. It is conceivable that our inventory shocks, which explain a large fraction of the volatility of both inventory types, mask an important endogenous propagation mechanism. We are however skeptical about this possibility. Our results suggest that inventory "innovations" are unlikely to be the driving forces of business cycles: this happens mostly because output inventory shocks generate substitution away from output inventories into consumption, so that their net effect on total output is small; and because input inventory shocks generate substitution away from input inventories into business investment, so that their net effect on total output is small. As a consequence, while the inventory shocks might have important consequences in terms of sectoral reallocation, they are not per se a driving force of business cycle fluctuations.

A Comparison between the Model and the Data. Figure 6 offers a visual check of the model's ability to reproduce key features of the data. We compare the empirical impulse responses and the model responses, which were obtained from the model's reduced form by ordering and orthogonalizing the model shocks, as was done in the VAR. ${ }^{44}$ In the first two columns of Table 9 , instead, we focus on some unconditional correlations in the data, and compare these with those of our estimated model. The central message is that our model accounts well for the volatility and comovement of the key model variables. In particular, the model simultaneously accounts for the volatility and procyclicality of inventory investment. ${ }^{45}$ It successfully mimics the greater volatility of input-inventory investment and its higher degree of procyclicality as compared to output-inventory investment. This result is true whether we look at the correlation between inventory investment and goods output, or the connection between changes in inventory investment and the change in GDP. Moreover, the model can reproduce the countercyclicality of the input-inventory target ratio, although not its magnitude, and the relative acyclicality of the output-inventory target ratio. Finally, the model successfully reproduces the relative volatilities of all types of investment.

\footnotetext{
${ }^{44}$ The impulse responses are based on a 6 -variable VAR with a constant and two lags and are based on the ordering shown in Figure 6.

${ }^{45}$ In Christiano (1988), it was necessary to rely on a more complex information structure in order to account for these two features of the data. He assumes that, at the time hours and capital decisions are made, firms observe the shocks with noise. Inventory and consumption decisions are, instead, made with full knowledge of the shocks. When there is no signal-extraction problem, his model can generate enough inventory-investment variability, but at the cost of a negative correlation between the change in inventory investment and output growth.
} 
To better gain insights into how our model achieves these results, it is useful to think of a reference model with zero depreciation rate for inventories. ${ }^{46}$ With this assumption, the model's ability to explain the behavior of inventories worsens dramatically. Figure 7 illustrates this result. With zero inventory depreciation rates, the response of fixed investment is essentially the same as in the unrestricted model, but the responses of both types of inventory investment are essentially zero. The positive response of inventories - relative to this counterfactual - in our estimated model enhances the amplification mechanism of a given productivity shock: the impact response of GDP rises from 0.6 to 0.7 percent.

This counterfactual exercise shows that positive depreciation is an essential feature to fit the volatilities of inventory investment. Differential adjustment costs (greater for fixed capital) are also important: in their absence, the volatility of business investment would be implausibly large (we do not report this experiment to avoid cluttering the figure). Absent depreciation, output inventories would be smooth due to standard consumption smoothing reasons. The intuition as to why input inventories become less volatile than fixed capital, if they do not depreciate, can be most easily provided when there are no adjustment costs. In this case, input inventories would respond to a productivity shock less than capital because these shocks have a larger effect on the marginal return to fixed capital. This occurs because a productivity shock has the same effect, percentage-wise, on the marginal return to fixed capital and inventories. When the depreciation rate on inventories is zero, and fixed capital must be compensated for the higher depreciation rate with a higher return, the absolute effect of a shock to the marginal return to capital is much greater in absolute value. As a result, capital would be more responsive to productivity shocks than input inventories. The bottom two panels of Figure 7 suggest that this effect is not undone by allowing for greater adjustment costs for capital at our estimated parameter values.

\subsection{Subsamples.}

Parameter Estimates. We re-estimate the model (with the same priors) over the subperiods 1960:1-1983:4 and 1984:1-2007:4. We allow $\sigma, \alpha, \theta_{g}, \theta_{s}$, and $\gamma$ to differ across subsamples to match the different sample means for the share of services in the economy and for the investment and the inventory ratios relative to goods output (reported in Table 3). This exercise allows us to investigate what lies at the root of the decline in output volatility since 1984, and what role, if any, inventories may have played in this regard. We should make clear, however, that our approach can only address a subset of the explanations of the Great Moderation that have been put forward in the literature. For instance, we cannot properly address the role of changes in policies in reducing output volatility.

Table 7 reports the results of the subsample estimation. With few exceptions, the full-sample parameter estimates lie between those for the two subsamples. Regarding the structure of the economy, some results are worth emphasizing. First, the depreciation rate for output inventories,

\footnotetext{
${ }^{46}$ This model is closer to Christiano's (1988) RBC model with inventories as a factor of production. His model assumes zero inventory depreciation.
} 
$F$, is smaller in the second part of the sample, as it goes from 5.6 to 4.6 percent. Second, output inventories and consumption become less substitutable ( $\mu$ increases). Third, the utilization function for capital in the service sector becomes more convex $\left(\zeta_{K s}\right.$ rises). Fourth, capital in the goods (service) sector becomes less (more) costly to adjust in the second period.

It is difficult to provide exhaustive explanations for the changes in these "deep" parameters of the model. Potential reasons for the lower estimate of the depreciation rate $\delta_{F}$ might be a change in the inventory mix or better inventory management in general. It is not clear how to interpret the change in adjustment costs for fixed capital, although the higher costs in the service sector might reflect: (1) the increased weight of innovative investment in the second subperiod and the greater associated costs in terms of learning and disruption; or (2) higher sector (or firm) specificity of capital goods.

We also find important changes in the parameters measuring the stochastic processes for technology and preferences. The most important result is that the volatility of general technology shocks in the goods and service sectors falls. They also become less correlated with each other. There is also a decrease in the volatility of the input-inventory shock, consistent with the idea that new methods of inventory management adopted since the early 1980s have made it easier to control the level of input inventories in efficiency units. However the decrease is not large.

Standard Deviations, Correlations and Variance Decompositions. Table 9 shows that, across the two subperiods, the model can reproduce the volatility decline in most macroeconomic aggregates. For instance, in our data, the standard deviation of detrended GDP falls by 0.77 percentage points between the 1960-1983 and 1984-2007 subperiods (from 1.89 to 1.12 percent). Our subsample estimates match the volatility decline, showing a reduction in the standard deviation of GDP of 0.76 percentage points. Our model also captures the decrease in the volatility of input inventories but not the one of output inventories. The model can also account for the reduced procyclicality of output inventory investment after 1983.

Table 8 shows how, in the second subperiod, output (input) inventory movements depend more (less) on their own innovations. As for the other variables, a larger fraction of the volatility in economic activity is due to demand-preference shocks: in the second part of the sample, the share of GDP variance that can be accounted for by discount rate shocks rises from about 15 percent to about 40 percent.

\subsection{The role of Inventories in the Great Moderation}

Prompted by the preceding results, a natural question is to what extent the reduced volatility of economic activity is due to a reduction in the volatility of the shocks - the "good luck" hypothesis - or to a change in the economy's structure. To answer this question, we partition the factors that can affect the implied volatility of the model variables into the following three sets:

1. Parameters that are estimated without using information on the steady-state ratios. This parameter set includes the autocorrelation of the shocks, the inventory depreciation rates, the 
elasticities of substitution, the adjustment costs, and the capital utilization parameters.

2. Parameters that are determined using steady-state information. When we estimate the model across subsamples, we choose values of $\alpha, \gamma, \sigma, \theta_{g}$, and $\theta_{s}$ that match the values of the ratios of input inventories to output and capital investment to output, plus the share of services in GDP, for each subperiod, conditional on the depreciation rates and the elasticities of substitution.

3. Parameters that measure the unconditional volatility of the shocks.

Table 10 breaks down how the three sets of parameters above contribute to the reduction in volatility captured by the model. Using the estimates obtained from the 1960-1983 sample as a reference point, we change one estimated parameter at a time, setting it to the value estimated for the 1984-2007 sample. This way, we can approximately measure each parameter's contribution to the change in volatility. The main result is that most of the reduction in GDP volatility is attributable to the reduction in the volatility of the underlying shocks - especially of the technology shock in the goods sector. This is consistent with the conclusions reached by Stock and Watson (2003) and Justiniano and Primiceri (2008). By themselves, smaller shocks can explain a reduction in GDP volatility of 0.52 percentage points (as measured by the standard deviation), compared to an estimated total decline of 0.76 percentage points. Most of the remainder is attributable to larger capacity-utilization costs, as well as the increased importance (share) of services in the economy. The latter, for instance, accounts for a quarter in the reduction in GDP volatility.

What about the role inventories may have played in the Great Moderation? There is a reduction in the volatility of input-inventory shocks, but it is small and it accounts only for about 0.01 percentage points of the total reduction in volatility of GDP and goods output. We also consider the effect of changes in $\alpha, \gamma, \sigma, \theta_{g}$, and $\theta_{s}$ implied by the changes in the steady-state ratios. Consider, for instance, the consequences of setting $M / Y_{g}$ equal to its post-1984 average value, while keeping all the other ratios and parameters - except $\alpha, \gamma, \sigma, \theta_{g}$, and $\theta_{s}$ - at the pre-1984 level: the decline in $M / Y_{g}$ is likely to be an indicator of better inventory control methods such as "just-in-time" or "flexible manufacturing systems." Such decline accounts for approximately 0.04 percentage points of the decrease in the volatility of GDP and 0.09 percentage points of the decrease in the volatility of output of the goods sector.

To summarize, our estimated model suggests that reductions in the volatility of the model's technological shocks account for most of the reduction in GDP volatility - a result generally consistent with the "good luck" hypothesis. Structural changes in the model's parameters have contributed to the reduction in GDP volatility by a smaller amount, working primarily through parameter changes that reduced the volatility of fixed investment. There is only a small role for inventory investment in the Great Moderation, associated with the decrease in the input inventories to output ratio. ${ }^{47}$

\footnotetext{
${ }^{47}$ This conclusion is consistent with Khan and Thomas (2007), who consider how aggregate volatility changes in a general equilibrium model following a decrease in fixed ordering costs.
} 


\section{Input and Output Inventories: More on Motivation and Extensions}

In this section we return to the arguments we have used to motivate the holding of inventories. We first explore in more detail the equivalence of the choice of introducing inventories in the utility function with the choice of including them in the budget constraint on the basis of the assumption that they affect shopping costs. We then provide a different model for input inventories that focuses on the notion that inventories are "used up" during the production process.

\subsection{The Role of Inventories in Reducing Shopping Costs}

Our formulation that treats output inventories as a good entering the utility function is convenient, simple and has interesting empirical properties. For example, it can rationalize why the ratio between output inventories and consumption is essentially acyclical, since the consumer (absent large fluctuations in the user cost of holding inventories) prefers to hold a relatively constant ratio of $F$ over $C_{g}$ over time. However, one might feel uncomfortable about putting output inventories in the utility function, when what output inventories really do is to make the consumer life easier by reducing shopping costs. This argument means that output inventories should essentially affect the consumer through the budget constraint, rather than the utility function. We can show that - at least for an empirically relevant, simpler version of the utility function - our model is equivalent to a model where output inventories do not enter the utility function at all, but affect the consumer via the budget constraint by affecting the cost of purchasing goods. The argument follows Feenstra (1986) who discusses the functional equivalence of including money in the utility function or liquidity costs in the budget constraint. These liquidity costs are decreasing in inventories and increasing in goods consumption and the functional form of the shopping cost function can be explicitly derived. Assume a unit elasticity of substitution between services and good consumption, as suggested by our estimates. In this case our utility function becomes:

$$
E_{0} \sum_{t=0}^{\infty} \beta^{t} \varepsilon_{\beta t}\left(\gamma \varepsilon_{\gamma t} \log X_{t}+\left(1-\gamma \varepsilon_{\gamma t}\right) \log C_{s t}-\tau\left(L_{g t}+L_{s t}\right)\right)
$$

with $X_{t}$ still equal to $\left(\alpha \varepsilon_{F t} C_{g t}^{-\mu}+\left(1-\alpha \varepsilon_{F t}\right) F_{t-1}^{-\mu}\right)^{-1 / \mu}$. It can be shown that this model yields the same equilibrium conditions as a model where inventories do not appear in the utility function, and the latter is written as: ${ }^{48}$

$$
E_{0} \sum_{t=0}^{\infty} \beta^{t} \varepsilon_{\beta t}\left(\gamma \varepsilon_{\gamma t} \log G_{t}+\left(1-\gamma \varepsilon_{\gamma t}\right) \log C_{s t}-\tau\left(L_{g t}+L_{s t}\right)\right),
$$

where $G_{t}$ denotes goods consumption net of shopping costs, so that $C_{g t}=G_{t}+\phi\left(G_{t}, F_{t}\right)$. The term $\phi\left(G_{t}, F_{t}\right)$ denotes the shopping cost function that appears an additional argument in the budget constraint, equation (2.4), and can be shown to take the following form:

$$
\phi\left(G_{t}, F_{t}\right)=\left(\left(\frac{1}{\alpha}-\frac{1-\alpha}{\alpha}\left(\frac{G_{t}}{F_{t}}\right)^{\mu}\right)^{-\frac{1}{\mu}}-1\right) G_{t} .
$$

\footnotetext{
${ }^{48}$ Appendix $\mathrm{C}$ discusses this equivalence in more detail.
} 
At our model estimates for $\alpha, \mu$ (and given the steady-state ratios implied by the data), the function $\phi\left(G_{t}, F_{t}\right)$ is decreasing and convex in the stock of output inventories. ${ }^{49}$. Moreover, one can estimate the transaction costs to be equal to approximately 2 percent of total goods output, which seems a reasonable number.

\subsection{A "Usage Only" Model of Input Inventories}

As we mentioned above, our model allows for a convenience yield of holding a larger stock of input inventories in producing value added. This convenience yield accrues in production over and above the usage of inventories, which is maximized out in deriving the value added production function. In other words, by focusing on value added (gross output minus materials used), one pushes the material usage decision in the background, but does not abstract from it.

In this section we outline and analyze an alternative model with no additional convenience yield and that focuses on the usage of material in producing gross output. ${ }^{50}$ This model is based on the following assumptions: (1) Only inventories that are "used up" augment society's ability to produce more gross output; (2) The usage of inventories depends upon the beginning of period stock. These considerations lead to a production function for gross output of the form:

$$
Y_{g t}=\left(A_{g t} L_{g t}\right)^{1-\theta_{g}}\left(\sigma\left(z_{g t} K_{g t-1}\right)^{-\nu}+(1-\sigma)\left(\varepsilon_{M t} z_{M t} M_{t-1}\right)^{-\nu}\right)^{-\theta_{g} / \nu},
$$

where $z_{M t}$ denotes the utilization rate of inventories, so that the term $z_{M t} M_{t-1}$ denotes inventories used in production. We also assume that higher utilization of inventories leads to a greater wastage, and hence, to higher depreciation in a convex fashion. As a result, the total "depreciation rate" for inventories is now the sum of three parts:

$$
d_{M t}=\delta_{M}+z_{M t}+a_{M t}\left(z_{M t}\right),
$$

where $\delta_{M}$ is a fixed component of the depreciation rate unrelated to usage and reflecting wastage and/or linear holding costs; the term $z_{M t}$ captures the usage of materials (proportional to the stock), and the term $a_{M t}$ describes the additional component of wastage that depends upon utilization in a convex fashion: this component reflects the idea that, at the margin, a higher or faster usage might provoke collateral damage to the remaining parts of the stock that are not directly used in production. Namely, we assume that $a_{M t}=R_{M}\left(\frac{\zeta_{M}}{2}-1+\left(1-\zeta_{M}\right) \frac{z_{M t}}{z_{M}}+\frac{\zeta_{M}}{2} \frac{z_{M t}^{2}}{z_{M}^{2}}\right)$, where $R_{M}=\frac{1}{\beta}=1-\delta_{M}$. The function $a_{M t}$ is convex in $z_{M t}$ and is normalized so that it equals zero when $z_{M t}$ equals the optimal, steady-state choice $z_{M} \cdot{ }^{51}$ In absence of direct estimates of the fraction of the stock of input

\footnotetext{
${ }^{49}$ See the Figure in Appendix C.

${ }^{50}$ Our Appendix D contains more complete details on this model.

${ }^{51}$ The assumption of convexity has two appealing properties: first, it allows us to solve the model using standard perturbation methods; second, and most importantly, it captures the idea that, at the margin, a higher utilization rate leads to a higher depreciation. Note that there are some analogies with the way we write down the utilization function for fixed capital. For fixed capital, we assume that the optimal (steady state) utilization rate of capital is unity, and normalize the utilization function so that no resources are wasted at the optimal utilization rate. Instead, here we normalize the function $a_{M t}$ so that the optimal steady state utilization rate is less than unity.
} 
inventories that is used in production, we set the steady-state, optimal utilization rate at 20 percent when taking the model to the data. The resource constraint is now:

$$
\begin{gathered}
Y_{g t}=C_{g t}+K_{g t}-\left(1-\delta_{K g}\left(z_{g t}\right)\right) K_{t-1}^{g}+K_{s t}-\left(1-\delta_{K s}\left(z_{s t}\right)\right) K_{t-1}^{s} \\
+F_{t}-\left(1-\delta_{F}\right) F_{t-1}+M_{t}-\left(1-\left(\delta_{M}+a_{M t}\right)\right) M_{t-1}+z_{M t} M_{t-1}+A C_{t} .
\end{gathered}
$$

where $A C_{t}$ denotes total adjustment costs. Value added in the goods sector is then obtained by subtracting materials used, $z_{M t} M_{t-1}$ from gross output, $Y_{g t}$.

We then estimate the model using the same priors of our baseline model (we estimate an additional parameter, $\zeta_{M}$, which measures the convexity of the utilization function). Table 11 reports the estimates. Figure 8 compares the impulse responses to a technology shock in the goods sector between the baseline model and the usage only model. The overall conclusion is that the two models yield similar impulse response functions and, more in general, have very similar implications for the business cycle properties of the variables of interest. One interesting difference is that the "usage only" model generates a high steady-state return on the stock of inventories - this happens because it implies a higher depreciation rate on the stock of inventories that is used in production -, thus enhancing somewhat the response of inventories to productivity shocks. While valuable and yielding some interesting results, this model is based on a set of assumptions that some would regard more stringent that those of our preferred model. Specifically, materials purchased in the period cannot be used immediately in production. Moreover, the assumption that greater use leads to greater depreciation in a convex fashion may be questioned.

\section{Conclusions}

The most important lesson of this paper is that an estimated DSGE model can incorporate inventories and fit the data reasonably well with plausible and interesting estimates of structural parameters that help characterize the role of input and output inventories. Each type of inventory investment plays a logically different role in the model and exhibits different degrees of volatility and procyclicality. The model can replicate the observed volatility and cyclicality of both input and output inventory investment, and particularly the fact that input-inventory investment is more volatile and procyclical than output-inventory investment. Moreover, the model can reproduce the countercyclicality of the input-inventory target ratio, and the relative acyclicality of the output-inventory target ratio. This finding represents a step forward relative to previous attempts to model inventories in DSGE models, especially given our model's ability to fit the data. Thus, our model provides a new, more expansive, and data-consistent framework for analyzing the cyclical properties of inventories.

When estimated across two subperiods, 1960-1983 and 1984-2007, the model captures the volatility reduction observed in aggregate variables, as well as the decline in procyclicality of outputinventory investment. However, the model suggests that the bulk of the Great Moderation is explained primarily by a reduction in the volatility of the technology shock in the goods sector (and of the discount rate shock). The reduction in the volatility of inventory shocks accounts for only a 
small portion of the decrease in output volatility. Nevertheless, the model's framework identifies several dimensions along which the economy's structure changed in an economically important manner, and contributed to the reduction in GDP volatility. Some of these structural changes are related to inventory behavior and influence the propagation role inventories play in the macroeconomy, but, at best, they have only played a minor role in accounting for the reduced volatility of output.

These conclusions are based on an estimated two-sector general equilibrium model that includes novel features such as the distinction between goods-producing and the services-producing sectors according to their inventory-holding behavior, and the distinction between input and output inventories. Non-zero inventory depreciation, which in the model provides an incentive to adjust inventories more in response to shocks, is another novel feature that is empirically important.

Despite the additional complexity, our model precludes an examination of certain aspects of inventory behavior that may be important to understanding business cycle fluctuations. First, we eschewed a richer examination of the stage-of-fabrication structure within the goods sector. For example, classifying inventories into only two types abstracts from the supply and distribution chains that pervade the actual input-output structure of the goods sector and probably play a vital role in the propagation of shocks. A second issue is that the model is silent on how markup variations and nominal features matter for inventory behavior and business cycles. Some inventory research examines how markup variation or interest rate policies influence inventory behavior. ${ }^{52}$ However, this work with nominal rigidities generally has not incorporated the stage-of-fabrication inventory distinction in a general equilibrium setting that we have advanced here. Third, we have sidestepped the micro-founded motivation for firms' holding of finished goods (output inventories): by focusing on the value of output inventories to households through utility and concentrating on the social planner's solution, we have not taken up a more detailed examination of the determinants of a firm's decision to hold output inventories in a market environment. We plan to address these issues in future work, and we hope that others will too.

\footnotetext{
${ }^{52}$ See footnote 3 for detailed references on this issue and on supply and distribution chains.
} 


\section{References}

[1] Ahmed, Shaghil, Andrew Levin, and Beth Anne Wilson. (2004) "Recent U.S. Macroeconomic Stability: Good Policies, Good Practices, or Good Luck?" Review of Economics and Statistics, 86(3), August, 824-832.

[2] An, Sungbae, and Frank Schorfheide (2007) "Bayesian analysis of DSGE models", Econometric Reviews, 26(2), 113-172

[3] Arias, Andres, Gary D. Hansen, and Lee E. Ohanian. (2006) "Why Have Business Cycle Fluctuations Become Less Volatile?" National Bureau of Economic Research (Cambridge, MA), Working Paper No. 12079, March.

[4] Baxter, Marianne and Robert G. King. (1999) "Measuring Business Cycles: Approximate BandPass Filters for Economic Time Series." Review of Economics and Statistics, 81(4), November, $575-593$.

[5] Bils, Mark and James A. Kahn. (2000) "What Inventory Behavior Tells Us about Business Cycles." American Economic Review, 90(3), June, 458-481.

[6] Bivin, David. (1988) "The Behavior of Manufacturers' Inventories: 1967-1986." Journal of Macroeconomics, 10(1), Winter, 63-81.

[7] Bivin, David. (1993) "The Influence of Inventories on Output and Prices: A Stage of Fabrication Approach." Journal of Macroeconomics, 15(4), Fall, 627-651.

[8] Blanchard, Olivier and John Simon. (2001) "The Long and Large Decline in U.S. Output Volatility." Brookings Papers on Economic Activity, 2001:1, 135-164.

[9] Blinder, Alan S. and Louis J. Maccini. (1991) "Taking Stock: A Critical Assessment of Recent Research on Inventories." Journal of Economic Perspectives, 5(1), Winter, 73-96.

[10] Boileau, Martin and Marc-Andre Letendre. (2004) "Inventory, Sticky Prices and the Propagation of Nominal Shocks." McMaster University (Hamilton, Ontario), Department of Economics Working Paper, April.

[11] Canova, Fabio. (2007) Methods for Applied Macroeconomic Research. Princeton, N.J.: Princeton University Press.

[12] Chang, Yongsung, Andreas Hornstein, and Pierre-Daniel G. Sarte. (2006) "Understanding How Employment Responds to Productivity Shocks in a Model with Inventories." Federal Reserve Bank of Richmond Working Paper No. 06-06, August.

[13] Chang, Yongsung, Taeyoung Doh, and Frank Schorfheide (2007). "Non-Stationary Hours in a DSGE Model", Journal of Money, Credit and Banking, 39(6), 1357-73.

[14] Chirinko, Robert S. (1993) "Business Fixed Investment Spending: Modeling Strategies, Empirical Results, and Policy Implications." Journal of Economic Literature, 31(4), December, $1875-1911$.

[15] Christiano, Lawrence J. (1988) "Why Does Inventory Investment Fluctuate So Much?" Journal of Monetary Economics, 21(2/3), March-May, 247-280. 
[16] Christiano, Lawrence J. (2004) "Lecture Notes." Advanced Workshop for Central Bankers (Northwestern University).

[17] Christiano, Lawrence J. and Terry J. Fitzgerald. (1989) "The Magnitude of the Speculative Motive for Holding Inventories in a Real Business Cycle Model." Federal Reserve Bank of Minneapolis Discussion Paper No. 10, January.

[18] Coen-Pirani, Daniele. (2004) "Markups, Aggregation, and Inventory Adjustment." American Economic Review, 94(5), December, 1328-1353.

[19] Cooley, Thomas and Edward Prescott. (1995), "Economic growth and business cycles", in Cooley, T. (ed.), Frontiers of Business Cycle Research, Princeton University Press: Princeton, 1-38.

[20] Cooper, Russell and John C. Haltiwanger. (1990) "Inventories and the Propagation of Sectoral Shocks." The American Economic Review, 80(1), March, 170-190.

[21] Davis, Steven J., and James A. Kahn. (2008). "Interpreting the Great Moderation: Changes in the Volatility of Economic Activity at the Macro and Micro Levels," Journal of Economic Perspectives, 22(4), Fall, 155-80.

[22] Del Negro, Marco and Frank Schorfheide (2008), "Forming Priors for DSGE Models (and How it Affects the Assessment of Nominal Rigidities)." Journal of Monetary Economics, 55(7), October, 1191-1208.

[23] Feenstra, Robert C. (1986) "Functional Equivalence between Liquidity Costs and the Utility of Money," Journal of Monetary Economics, 17(2), March, 271-291.

[24] Feldstein, Martin S. and Alan Auerbach. (1976) "Inventory Behavior in Durable-Goods Manufacturing: The Target-Adjustment Model." Brookings Papers on Economic Activity, 1976:2, 351-396.

[25] Feroli, Michael. (2002) "An Equilibrium Model of Inventories with Investment-Specific Technical Change." Princeton University, unpublished working paper, September.

[26] Fisher, Jonas D. M. and Andreas Hornstein. (2000) "(S,s) Inventory Policies in General Equilibrium." Review of Economic Studies, 67(1), January, 117-145.

[27] Gomme, Paul, and Peter Rupert. (2007). "Theory, Measurement and Calibration of Macroeconomic Models." Journal of Monetary Economics, 54(2), March, 460-497.

[28] Greenwood, Jeremy, Zvi Hercowitz, and Per Krusell. (2000) "The Role of Investment-Specific Technological Change in the Business Cycle." European Economic Review, 44(1), January, 91115.

[29] Hansen, Gary D. (1985) "Indivisible Labor and the Business Cycle." Journal of Monetary Economics, $16(3)$, November, 309-327.

[30] Herrera, Ana Maria and Elena Pesavento. (2005) "The Decline in U.S. Output Volatility: Structural Changes and Inventory Investment." Journal of Business and Economic Statistics, 23(4), October, 462-472. 
[31] Hornstein, Andreas and Pierre-Daniel Sarte. (2001) "Sticky Prices and Inventories: Production Smoothing Reconsidered." Federal Reserve Bank of Richmond Working Paper No. 01-6, March.

[32] Huang, Kevin X. D. and Zheng Liu. (2001) "Production Chains and General Equilibrium Aggregate Dynamics." Journal of Monetary Economics, 48(2), October, 437-462.

[33] Humphreys, Brad R., Louis J. Maccini, and Scott Schuh. (2001) "Input and Output Inventories." Journal of Monetary Economics, 47(2), April, 347-375.

[34] Husted, Steven and Tryphon Kollintzas. (1987) "Linear Rational Expectations Equilibrium Laws of Motion for Selected U.S. Raw Material Imports." International Economic Review, October, $28(3), 651-70$.

[35] Ireland, Peter N. (2004) "Technology Shocks in the New Keynesian Model." Review of Economics and Statistics, 86(4), November, 923-936.

[36] Irvine, F. Owen. (2005) "Trend Breaks in U.S. Inventory to Sales Ratios." International Journal of Production Economics, 93-94(0), January, Special Issue, 13-23.

[37] Irvine, F. Owen and Scott Schuh. (2005a) "The Roles of Comovement and Inventory Investment in the Reduction of Output Volatility." Federal Reserve Bank of Boston Working Paper No. 0509, July.

[38] Irvine, F. Owen and Scott Schuh. (2005b) "Inventory Investment and Output Volatility." International Journal of Production Economics, 93-94(0), January, Special Issue, 75-86.

[39] Jung, Yongseung and Tack Yun. (2006) "Monetary Policy Shocks, Inventory Dynamics, and Price-Setting Behavior." Federal Reserve Bank of San Francisco Working Paper 2006-02, August.

[40] Justiniano, Alejandro and Giorgio E. Primiceri (2008) "The Time-Varying Volatility of Macroeconomic Fluctuations," American Economic Review, $98(3)$, 604-41, June.

[41] Kahn, James A. (1987) "Inventories and the Volatility of Production." The American Economic Review, 77(4), September, 667-679.

[42] Kahn, James A. and Margaret M. McConnell. (2005) "Making Sense of Inventory-Sales Ratios." Unpublished working paper, Federal Reserve Bank of New York, August.

[43] Kahn, James A., Margaret M. McConnell, and Gabriel Perez-Quiros. (2002) "On the Causes of the Increased Stability of the U.S. Economy." Economic Policy Review, 8(1), Federal Reserve Bank of New York, May, 183-202.

[44] Khan, Aubhik, and Julia K. Thomas. (2007) "Inventories and the Business Cycle: An Equilibrium Analysis of (S, s) Policies." The American Economic Review, 97(4), September, 1165-88.

[45] Kimball, Miles S. (1994) "Proof of Consumption Sector Neutrality." Unpublished working paper, University of Michigan, August.

[46] Kimura, Takeshi, and Kyosuke Shiotani. (2009) "Stabilized Business Cycles with Increased Output Volatility at High Frequencies," Journal of the Japanese and International Economies, 23(1), March, 1-19.. 
[47] Kongsamut, Piyabha, Sergio Rebelo and Danyang Xie. (2001) "Beyond Balanced Growth," Review of Economic Studies, 68(4), October, 869-82.

[48] Kuznets, Simon. (1957) "Quantitative Aspects of the Economic Growth of Nations II: Industrial Distribution of National Product and Labor Force." Economic Development and Cultural Change V (4, supplement), 3-111.

[49] Kydland, Finn E. and Edward C. Prescott. (1982) "Time to Build and Aggregate Fluctuations." Econometrica, $50(6)$, November, 1345-1370.

[50] Leduc, Sylvain and Keith Sill. (2006) "Monetary Policy, Oil Shocks, and TFP: Accounting for the Decline in U.S. Volatility." Board of Governors of the Federal Reserve System, International Finance Discussion Paper No. 873.

[51] Lee, Donghoon and Kenneth I. Wolpin. (2006) "Intersectoral Labor Mobility and the Growth of the Service Sector." Econometrica, 74(1), January, 1-46.

[52] Lovell, Michael C. (1961) "Manufacturers' Inventories, Sales Expectations, and the Acceleration Principle." Econometrica, 29(3), July, 293-314.

[53] Maccini, Louis J. and Adrian Pagan. (2007) "Exploring the Role of Inventories in Business Cycles." Unpublished working paper, John Hopkins University.

[54] Marquis, Milton and Bharat Trehan. (2005a) "Accounting for the Secular 'Decline' of U.S. Manufacturing." Federal Reserve Bank of San Francisco Working Papers in Applied Economic Theory and Econometrics No. 2005-18, September.

[55] Marquis, Milton and Bharat Trehan. (2005b) "On Using Relative Prices to Measure Capitalspecific Technological Progress." Federal Reserve Bank of San Francisco Working Papers in Applied Economic Theory and Econometrics No. 2005-02.

[56] McConnell, Margaret M. and Gabriel Perez-Quiros. (2000) "Output Fluctuations in the United States: What Has Changed Since the Early 1980s?" The American Economic Review, 90(5), December, 1464-1476.

[57] Pindyck, Robert S. (1994) "Inventories and the Short-Run Dynamics of Commodity Prices." RAND Journal of Economics, 25(1), Spring, 141-159.

[58] Ramey, Valerie A. (1989) "Inventories as Factors of Production and Economic Fluctuations." The American Economic Review, 79(3), June, 338-354.

[59] Ramey, Valerie A. and Daniel J. Vine. (2004) "Why Do Real and Nominal Inventory-Sales Ratios Have Different Trends?" Journal of Money, Credit, and Banking, 36(5), October, 959-963.

[60] Ramey, Valerie A. and Daniel J. Vine. (2006) "Declining Volatility in the U.S. Automobile Industry," The American Economic Review, 96(4), December, 1876-1889.

[61] Ramey, Valerie A. and Kenneth D. West. (1999) "Inventories." In Handbook of Macroeconomics, Volume 1B, edited by John B. Taylor and Michael Woodford, 863-923. Amsterdam: Elsevier Science. 
[62] Rogerson, Richard. (1988) "Indivisible Labor, Lotteries and Equilibrium." Journal of Monetary Economics, 21(1), January, 3-16.

[63] Rotemberg, Julio and Michael Woodford (1995), "Dynamic General Equilibrium Models with Imperfectly Competitive Product Markets," in Thomas Cooley, ed., Frontiers of Business Cycle Research Princeton University Press: Princeton NJ.

[64] Rossana, Robert J. (1990) "Interrelated Demands for Buffer Stocks and Productive Inputs: Estimates for Two-Digit Manufacturing Industries." Review of Economics and Statistics, 72(1), February, 19-29.

[65] Stock, James H. and Mark W. Watson. (2003) "Has the Business Cycle Changed and Why?" In NBER Macroeconomics Annual 2002, edited by Mark Gertler and Kenneth Rogoff, 159-218. Cambridge and London: MIT Press.

[66] Stock, James R. and Douglas Lambert. (2001), Strategic Logistics Management, 4th Ed., McGraw-Hill Irwin.

[67] Smets, Frank and Raf Wouters. (2003) "An Estimated Dynamic Stochastic General Equilibrium Model of the Euro Area." Journal of the European Economic Association, 1(5), September, $1123-1175$.

[68] Wen, Yi. (2005a) "The Multiplier: A General equilibrium Analysis of Multi-Stage-Fabrication Economy with Inventories." Federal Reserve Bank of St. Louis Working Paper No. 2005-046A, June.

[69] Wen, Yi. (2005b) "Durable Good Inventories and the Volatility of Production: Explaining the Less Volatile U.S. Economy." Federal Reserve Bank of St. Louis Working Paper No. 2005-047A, June.

[70] Wen, Yi. (2005c) "Understanding the Inventory Cycle." Journal of Monetary Economics, 52(8), November, $1533-1555$.

[71] Whelan, Karl. (2002) "A Guide to U.S. Chain Aggregated NIPA Data." Review of Income and Wealth, 48(2), June, 217-233.

[72] Whelan, Karl. (2003) "A Two-Sector Approach to Modeling U.S. NIPA Data." Journal of Money, Credit, and Banking, 35(4), August, 627-656. 


\begin{tabular}{|c|c|c|c|}
\hline \multicolumn{2}{|l|}{ Sectors $(\%)$} & \multirow{2}{*}{ NAICS Industries } & \multirow{2}{*}{$\begin{array}{l}\text { GDP Share } \\
(\%)\end{array}$} \\
\hline Model & NIPA & & \\
\hline \multirow{7}{*}{$\begin{array}{c}\text { Goods }(35.9) \\
{[\text { Excluding government (40.1)] }}\end{array}$} & \multirow{4}{*}{ Goods (21.2) } & Agriculture & 1.0 \\
\hline & & Mining & 1.2 \\
\hline & & Manufacturing & 14.5 \\
\hline & & Construction & 4.4 \\
\hline & \multirow{11}{*}{ Services (78.8) } & Utilities & 1.9 \\
\hline & & Wholesale Trade & 6.0 \\
\hline & & Retail Trade & 6.7 \\
\hline \multirow{7}{*}{$\begin{array}{c}\text { Services }(51.8) \\
{[\text { Excluding government (59.1)] }}\end{array}$} & & Transportation & 3.1 \\
\hline & & Information & 4.7 \\
\hline & & FIREL & 19.7 \\
\hline & & Services, business & 11.6 \\
\hline & & Education \& Health & 6.9 \\
\hline & & Leisure & 3.6 \\
\hline & & Other services & 2.3 \\
\hline Government (12.3) & & Government & 12.3 \\
\hline
\end{tabular}

Table 1: Sector Definitions and Output Shares

Notes: FIREL denotes Finance, Insurance, Real Estate, and Leasing.

\begin{tabular}{|c|c|c|c|}
\hline \multicolumn{2}{|c|}{ Model Inventories } & NIPA Inventories (NAICS) & \multirow{2}{*}{$\begin{array}{l}2000 \text { Share } \\
\text { (in percent) }\end{array}$} \\
\hline Input \& Output & Stage-of-Fabrication & Industry & \\
\hline \multirow{11}{*}{ Input $(73.4 \%)$} & \multirow{6}{*}{ Raw Materials (18.9\%) } & Agriculture & 8.6 \\
\hline & & Mining, utilities, construction (MUC) & 2.9 \\
\hline & & Mining & n.a. \\
\hline & & Utilities & n.a. \\
\hline & & Construction & n.a. \\
\hline & & Other & 7.4 \\
\hline & \multirow{5}{*}{ Work-in-process $(54.5 \%)$} & Manufacturing & 31.1 \\
\hline & & Materials and supplies & 11.0 \\
\hline & & Work-in-process & 8.9 \\
\hline & & Finished goods & 11.1 \\
\hline & & Wholesale trade & 23.4 \\
\hline Output $(26.6 \%)$ & Finished goods $(26.6 \%)$ & Retail trade & 26.6 \\
\hline
\end{tabular}

Table 2: Inventory Stock Definitions and Shares 


\begin{tabular}{cccc}
\hline \hline & Full sample & $1960-1983$ & $1984-2007$ \\
\hline$F / Y_{g}$ & 0.34 & 0.30 & 0.36 \\
$M / Y_{g}$ & 1.16 & 1.37 & 1.07 \\
$K_{g} / Y_{g}$ & 4.59 & 5.26 & 4.29 \\
$K_{s} / Y_{g}$ & 9.32 & 8.22 & 9.82 \\
$Y_{s}^{\prime} / Y_{g}$ & 0.81 & 0.54 & 0.88 \\
\hline
\end{tabular}

Table 3: Target Steady-State Ratios of the Model

Notes: Output is expressed in quarterly units. The last row is the ratio of nominal output of services over nominal output of the goods sector. The capital output ratios are calculated from the investment-to-output ratios, assuming depreciation rates of $\delta_{K g}=.02$ and $\delta_{K s}=.02$.

\begin{tabular}{ccccccc}
\hline \hline & \multicolumn{3}{c}{ Prior } & \multicolumn{3}{c}{ Full Sample } \\
& Mean & Distribution & St.dev. & Mean & $5 \%$ & $95 \%$ \\
\hline$\delta_{F}$ & 0.020 & beta & 0.01 & $\mathbf{0 . 0 8 1}$ & 0.055 & 0.110 \\
$\delta_{M}$ & 0.020 & beta & 0.01 & $\mathbf{0 . 0 2 2}$ & 0.013 & 0.032 \\
$1+\mu$ & 1.500 & norm & 0.5 & $\mathbf{1 . 3 0}$ & 0.88 & 1.74 \\
$1+\nu$ & 1.500 & norm & 0.5 & $\mathbf{3 . 6 0}$ & 3.09 & 4.13 \\
$1+\phi$ & 1.500 & norm & 0.5 & $\mathbf{1 . 0 3}$ & 1.01 & 1.07 \\
$\psi_{F} /\left(1+\psi_{F}\right)$ & 0.500 & beta & 0.2 & $\mathbf{0 . 0 3}$ & 0.02 & 0.04 \\
$\psi_{K g} /\left(1+\psi_{K g}\right)$ & 0.500 & beta & 0.2 & $\mathbf{0 . 2 0}$ & 0.14 & 0.35 \\
$\psi_{K s} /\left(1+\psi_{K s}\right)$ & 0.500 & beta & 0.2 & $\mathbf{0 . 4 7}$ & 0.28 & 0.65 \\
$\psi_{M} /\left(1+\psi_{M}\right)$ & 0.500 & beta & 0.2 & $\mathbf{0 . 0 2}$ & 0.01 & 0.04 \\
$\rho_{g}$ & 0.750 & beta & 0.1 & $\mathbf{0 . 8 6}$ & 0.83 & 0.90 \\
$\rho_{\beta}$ & 0.750 & beta & 0.1 & $\mathbf{0 . 9 3}$ & 0.90 & 0.96 \\
$\rho_{F}$ & 0.750 & beta & 0.1 & $\mathbf{0 . 9 2}$ & 0.86 & 0.96 \\
$\rho_{\gamma}$ & 0.750 & beta & 0.1 & $\mathbf{0 . 8 6}$ & 0.80 & 0.91 \\
$\rho_{M}$ & 0.750 & beta & 0.1 & $\mathbf{0 . 9 4}$ & 0.91 & 0.96 \\
$\rho_{s}$ & 0.750 & beta & 0.1 & $\mathbf{0 . 9 4}$ & 0.91 & 0.96 \\
$\zeta_{K g} /\left(1+\zeta_{K g}\right)$ & 0.500 & beta & 0.2 & $\mathbf{0 . 9 5}$ & 0.89 & 0.99 \\
$\zeta_{K s} /\left(1+\zeta_{K s}\right)$ & 0.500 & beta & 0.2 & $\mathbf{0 . 8 0}$ & 0.62 & 0.94 \\
& & & & & & \\
$\sigma_{g}$ & 0.025 & invg & Inf & $\mathbf{1 . 4 9 \%}$ & $1.29 \%$ & $1.72 \%$ \\
$\sigma_{\beta}$ & 0.025 & invg & Inf & $\mathbf{3 . 8 0 \%}$ & $2.57 \%$ & $5.59 \%$ \\
$\sigma_{F}$ & 0.01 & invg & Inf & $\mathbf{0 . 3 3 \%}$ & $0.25 \%$ & $0.42 \%$ \\
$\sigma_{\gamma}$ & 0.01 & invg & Inf & $\mathbf{0 . 6 5 \%}$ & $0.54 \%$ & $0.80 \%$ \\
$\sigma_{M}$ & 0.05 & invg & Inf & $\mathbf{1 0 . 3 4 \%}$ & $8.00 \%$ & $13.18 \%$ \\
$\sigma_{s}$ & 0.025 & invg & Inf & $\mathbf{1 . 5 2 \%}$ & $1.21 \%$ & $1.92 \%$ \\
$\sigma_{g, s}$ & 0.50 & norm & 0.25 & $\mathbf{0 . 7 2}$ & 0.65 & 0.78 \\
\hline & & & & & &
\end{tabular}

Table 4: Prior Distributions and Parameter Estimates, Full Sample 


\begin{tabular}{cccc}
\hline \hline & Full sample & $1960-1983$ & $1984-2007$ \\
\hline$\alpha$ & 0.9668 & 0.9768 & 0.9788 \\
$\gamma$ & 0.4710 & 0.5686 & 0.4407 \\
$\sigma$ & 0.9926 & 0.9843 & 0.9856 \\
$\theta_{g}$ & 0.1665 & 0.1934 & 0.1570 \\
$\theta_{s}$ & 0.3268 & 0.4408 & 0.3237 \\
\hline
\end{tabular}

Table 5: Values of the Share Parameters Implied by the Estimation Results

\begin{tabular}{ccccccc}
\hline \hline \multicolumn{7}{c}{ Full Sample } \\
& $\sigma_{g}$ & $\sigma_{\beta}$ & $\sigma_{F}$ & $\sigma_{\gamma}$ & $\sigma_{M}$ & $\sigma_{s}$ \\
\hline$\widehat{Y_{g}}$ & 65.9 & 28.4 & 2.1 & 2.3 & 1.3 & 0.001 \\
$\widehat{Y}_{s}$ & 1.1 & 0.4 & 0.01 & 26.4 & 0.1 & 72.0 \\
$\widetilde{I}$ & 30.3 & 60.5 & 0.1 & 0.3 & 8.9 & 0.0 \\
$\widetilde{\Delta F}$ & 11.3 & 3.7 & 83.4 & 0.4 & 1.3 & 0.0 \\
$\widetilde{\Delta M}$ & 12.4 & 21.3 & 0.1 & 0.0 & 66.2 & 0.0 \\
$\widehat{C_{g}}$ & 64.6 & 10.8 & 5.6 & 13.4 & 5.6 & 0.01 \\
$\widehat{G D P}$ & 66.3 & 26.0 & 1.4 & 0.01 & 0.8 & 5.5 \\
\hline
\end{tabular}

Table 6: Variance Decompositions of the Model, Full Sample

Notes: For each variable, the columns indicate the fractions of the total variance explained by each shock. Variables with a hat are scaled by their steady-state value. Variables with a tilde are scaled by steady-state goods output. 


\begin{tabular}{cccccccccc}
\hline \hline & & Prior & \multicolumn{3}{c}{$\mathbf{1 9 6 0 - 1 9 8 3}$} & \multicolumn{3}{c}{$\mathbf{1 9 8 4 - 2 0 0 7}$} \\
& & & & Mean & $5 \%$ & $95 \%$ & Mean & $5 \%$ & $95 \%$ \\
\hline$\delta_{F}$ & 0.020 & beta & 0.01 & $\mathbf{0 . 0 5 6}$ & 0.033 & 0.082 & $\mathbf{0 . 0 4 6}$ & 0.023 & 0.074 \\
$\delta_{M}$ & 0.020 & beta & 0.01 & $\mathbf{0 . 0 2 2}$ & 0.013 & 0.034 & $\mathbf{0 . 0 2 2}$ & 0.013 & 0.035 \\
$1+\mu$ & 1.500 & norm & 0.5 & $\mathbf{1 . 1 3}$ & 0.64 & 1.62 & $\mathbf{1 . 4 0}$ & 0.79 & 2.03 \\
$1+\nu$ & 1.500 & norm & 0.5 & $\mathbf{3 . 1 3}$ & 2.57 & 3.70 & $\mathbf{3 . 0 8}$ & 2.67 & 3.56 \\
$1+\phi$ & 1.500 & norm & 0.5 & $\mathbf{0 . 9 3}$ & 0.82 & 0.98 & $\mathbf{1 . 1 6}$ & 1.07 & 1.31 \\
$\psi_{F} /\left(1+\psi_{F}\right)$ & 0.500 & beta & 0.2 & $\mathbf{0 . 0 2}$ & 0.01 & 0.03 & $\mathbf{0 . 0 4}$ & 0.02 & 0.06 \\
$\psi_{K g} /\left(1+\psi_{K g}\right)$ & 0.500 & beta & 0.2 & $\mathbf{0 . 2 7}$ & 0.15 & 0.60 & $\mathbf{0 . 1 6}$ & 0.09 & 0.29 \\
$\psi_{K s} /\left(1+\psi_{K s}\right)$ & 0.500 & beta & 0.2 & $\mathbf{0 . 5 0}$ & 0.23 & 0.77 & $\mathbf{0 . 6 1}$ & 0.30 & 0.84 \\
$\psi_{M} /\left(1+\psi_{M}\right)$ & 0.500 & beta & 0.2 & $\mathbf{0 . 0 4}$ & 0.02 & 0.06 & $\mathbf{0 . 0 2}$ & 0.01 & 0.04 \\
$\rho_{g}$ & 0.750 & beta & 0.1 & $\mathbf{0 . 8 4}$ & 0.79 & 0.89 & $\mathbf{0 . 9 2}$ & 0.86 & 0.98 \\
$\rho_{\beta}$ & 0.750 & beta & 0.1 & $\mathbf{0 . 9 3}$ & 0.89 & 0.95 & $\mathbf{0 . 9 2}$ & 0.87 & 0.95 \\
$\rho_{F}$ & 0.750 & beta & 0.1 & $\mathbf{0 . 9 5}$ & 0.90 & 0.98 & $\mathbf{0 . 9 4}$ & 0.89 & 0.97 \\
$\rho_{\gamma}$ & 0.750 & beta & 0.1 & $\mathbf{0 . 8 5}$ & 0.76 & 0.92 & $\mathbf{0 . 8 8}$ & 0.81 & 0.95 \\
$\rho_{M}$ & 0.750 & beta & 0.1 & $\mathbf{0 . 9 5}$ & 0.92 & 0.97 & $\mathbf{0 . 9 7}$ & 0.95 & 0.98 \\
$\rho_{s}$ & 0.750 & beta & 0.1 & $\mathbf{0 . 9 4}$ & 0.90 & 0.97 & $\mathbf{0 . 9 5}$ & 0.93 & 0.98 \\
$\zeta_{K g} /\left(1+\zeta_{K g}\right)$ & 0.500 & beta & 0.2 & $\mathbf{0 . 9 1}$ & 0.80 & 0.98 & $\mathbf{0 . 9 0}$ & 0.79 & 0.98 \\
$\zeta_{K s} /\left(1+\zeta_{K s}\right)$ & 0.500 & beta & 0.2 & $\mathbf{0 . 3 7}$ & 0.17 & 0.57 & $\mathbf{0 . 8 8}$ & 0.74 & 0.97 \\
& & & & & & & & & \\
$\sigma_{g}$ & 0.025 & invg & Inf & $\mathbf{1 . 9 1 \%}$ & $1.59 \%$ & $2.28 \%$ & $\mathbf{1 . 5 1 \%}$ & $1.03 \%$ & $2.63 \%$ \\
$\sigma_{\beta}$ & 0.025 & invg & Inf & $\mathbf{3 . 8 3 \%}$ & $2.47 \%$ & $5.63 \%$ & $\mathbf{3 . 1 7 \%}$ & $1.91 \%$ & $4.85 \%$ \\
$\sigma_{F}$ & 0.01 & invg & Inf & $\mathbf{0 . 3 8 \%}$ & $0.28 \%$ & $0.50 \%$ & $\mathbf{0 . 4 7 \%}$ & $0.33 \%$ & $0.62 \%$ \\
$\sigma_{\gamma}$ & 0.01 & invg & Inf & $\mathbf{0 . 5 1 \%}$ & $0.40 \%$ & $0.67 \%$ & $\mathbf{0 . 7 8 \%}$ & $0.58 \%$ & $1.13 \%$ \\
$\sigma_{M}$ & 0.05 & invg & Inf & $\mathbf{1 4 . 1 \%}$ & $10.5 \%$ & $18.9 \%$ & $\mathbf{1 2 . 8 \%}$ & $9.4 \%$ & $16.4 \%$ \\
$\sigma_{s}$ & 0.025 & invg & Inf & $\mathbf{1 . 7 0 \%}$ & $1.31 \%$ & $2.26 \%$ & $\mathbf{1 . 4 9 \%}$ & $1.15 \%$ & $1.96 \%$ \\
$\sigma_{g, s}$ & 0.50 & norm & 0.25 & $\mathbf{0 . 7 2}$ & 0.61 & 0.81 & $\mathbf{0 . 4 4}$ & 0.29 & 0.59 \\
\hline & & & & & & & & &
\end{tabular}

Table 7: Parameter Estimates, Subsamples 


\begin{tabular}{ccccccc}
\hline \hline \multicolumn{7}{c}{$1960-1983$} \\
& $\sigma_{g}$ & $\sigma_{\beta}$ & $\sigma_{F}$ & $\sigma_{\gamma}$ & $\sigma_{M}$ & $\sigma_{s}$ \\
\hline$\widehat{Y_{g}}$ & 79.0 & 17.9 & 1.8 & 0.7 & 0.6 & 0.001 \\
$\widehat{Y_{s}}$ & 12.3 & 0.8 & 0.0 & 38.6 & 1.5 & 46.8 \\
$\widetilde{I}$ & 43.9 & 40.7 & 0.1 & 1.2 & 14.1 & 0.002 \\
$\widetilde{\Delta F}$ & 12.7 & 4.7 & 81.0 & 0.1 & 1.5 & 0.0 \\
$\widetilde{\Delta M}$ & 17.4 & 19.7 & 0.1 & 0.0 & 62.8 & 0.0 \\
$\widehat{C_{g}}$ & 69.0 & 7.3 & 5.1 & 7.4 & 11.2 & 0.03 \\
$\widehat{G D P}$ & 81.6 & 14.9 & 1.3 & 0.1 & 0.4 & 1.6
\end{tabular}

1984-2007

\begin{tabular}{ccccccc} 
& $\sigma_{g}$ & $\sigma_{\beta}$ & $\sigma_{F}$ & $\sigma_{\gamma}$ & $\sigma_{M}$ & $\sigma_{s}$ \\
\hline$\widehat{Y_{g}}$ & 49.4 & 41.9 & 3.7 & 3.7 & 1.2 & 0.02 \\
$\widehat{Y}_{s}$ & 1.3 & 0.3 & 0.2 & 30.8 & 0.1 & 67.3 \\
$\widetilde{I}$ & 21.2 & 68.7 & 0.1 & 0.1 & 9.9 & 0.0 \\
$\widetilde{\Delta F}$ & 2.3 & 3.7 & 93.6 & 0.1 & 0.3 & 0.001 \\
$\widetilde{\Delta M}$ & 7.9 & 30.7 & 0.1 & 0.01 & 61.3 & 0.0 \\
$\widehat{C_{g}}$ & 65.9 & 6.6 & 8.3 & 12.8 & 6.2 & 0.2 \\
$\widehat{G D P}$ & 51.5 & 39.0 & 2.5 & 0.1 & 0.8 & 6.2 \\
\hline
\end{tabular}

Table 8: Variance Decompositions, Subsamples 


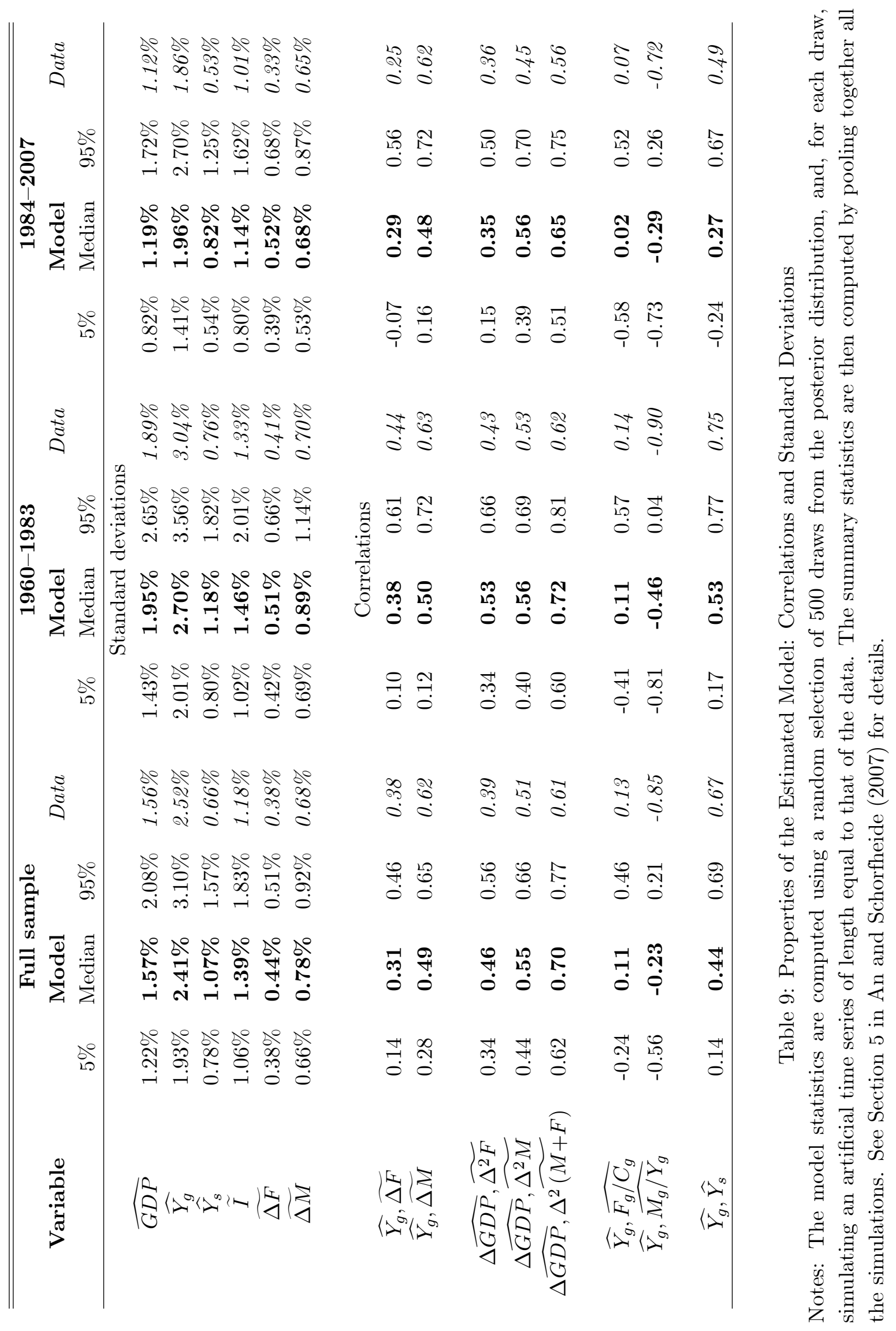




\begin{tabular}{|c|c|c|c|c|c|c|}
\hline \multirow[b]{2}{*}{ Parameter } & \multicolumn{2}{|c|}{ Value } & \multicolumn{4}{|c|}{ Contribution to change $(\times 100)$} \\
\hline & 1960-1983 & 1984-2007 & $\sigma(\widehat{G D P})$ & $\sigma\left(\widehat{Y_{g}}\right)$ & $\sigma\left(\widehat{Y}_{s}\right)$ & $\sigma(\widetilde{I})$ \\
\hline$\delta_{F}$ & 0.056 & 0.046 & 0.00 & 0.00 & 0.01 & -0.01 \\
\hline$\delta_{M}$ & 0.022 & 0.022 & -0.01 & -0.02 & 0.00 & -0.01 \\
\hline $1+\mu$ & 1.13 & 1.40 & -0.01 & -0.02 & 0.00 & -0.01 \\
\hline $1+\nu$ & 3.13 & 3.08 & 0.00 & -0.01 & 0.00 & 0.00 \\
\hline $1+\phi$ & 0.93 & 1.16 & 0.02 & -0.03 & -0.01 & -0.05 \\
\hline$\psi_{F} /\left(1+\psi_{F}\right)$ & 0.02 & 0.04 & 0.00 & -0.01 & 0.01 & 0.01 \\
\hline$\psi_{K g} /\left(1+\psi_{K g}\right)$ & 0.27 & 0.16 & 0.21 & 0.36 & 0.00 & 0.42 \\
\hline$\psi_{K s} /\left(1+\psi_{K s}\right)$ & 0.50 & 0.61 & -0.08 & -0.13 & -0.01 & -0.16 \\
\hline$\psi_{M} /\left(1+\psi_{M}\right)$ & 0.04 & 0.02 & 0.03 & 0.06 & 0.00 & 0.00 \\
\hline$\zeta_{K g} /\left(1+\zeta_{K g}\right)$ & 0.91 & 0.90 & -0.02 & -0.02 & -0.01 & -0.01 \\
\hline$\zeta_{K s} /\left(1+\zeta_{K s}\right)$ & 0.37 & 0.88 & -0.16 & -0.12 & -0.24 & -0.13 \\
\hline All estimated parameters & & & 0.06 & 0.19 & -0.27 & 0.14 \\
\hline$F / Y_{g}$ & 0.30 & 0.36 & 0.01 & 0.01 & 0.00 & -0.01 \\
\hline$M / Y_{g}$ & 1.37 & 1.07 & -0.04 & -0.09 & 0.01 & -0.04 \\
\hline$\left(K_{g}+K_{s}\right) / Y_{g}$ & 13.48 & 14.11 & 0.06 & 0.09 & -0.04 & 0.00 \\
\hline$Y_{s}^{\prime} / Y_{g}$ & 0.54 & 0.88 & -0.20 & 0.00 & 0.01 & 0.00 \\
\hline All steady state parameters & & & -0.16 & 0.04 & -0.01 & -0.06 \\
\hline$\sigma_{g}$ & $1.91 \%$ & $1.51 \%$ & -0.29 & -0.40 & -0.05 & -0.10 \\
\hline$\sigma_{F}$ & $0.38 \%$ & $0.47 \%$ & 0.01 & 0.02 & 0.01 & 0.00 \\
\hline$\sigma_{M}$ & $14.13 \%$ & $12.77 \%$ & -0.01 & -0.01 & -0.01 & -0.01 \\
\hline All shocks & & & -0.52 & -0.64 & -0.06 & -0.25 \\
\hline All parameters and shocks & & & -0.76 & -0.73 & -0.35 & -0.30 \\
\hline
\end{tabular}

Table 10: Accounting for the Decline in Volatility

Notes: Columns 2 and 3 indicate the estimated value of the parameter in the first column in each subsample. In the last four columns, we take the period 1960-1983 as the baseline period and change each parameter to its 1984-2004 value to account for its contribution to reducing volatility. The columns indicate, for each variable, the change in the standard deviation (times 100) due to the change in that parameter. Two important caveats are that: (1) standard deviations are not additive; (2) the effects of each model parameter are not independent from the values of other model parameters. For this reason, the values in each column do not add up to the last value listed in the column. 


\begin{tabular}{cccccccc}
\hline \hline & \multicolumn{3}{c}{ Prior } & \multicolumn{5}{c}{ Usage Model } & Baseline Model \\
& Mean & Distrib. & St.dev. & Mean & $5 \%$ & $95 \%$ & Mean \\
\hline$\delta_{F}$ & 0.020 & beta & 0.01 & $\mathbf{0 . 0 7 8}$ & 0.053 & 0.106 & $\mathbf{0 . 0 8 1}$ \\
$\delta_{M}$ & 0.020 & beta & 0.01 & $\mathbf{0 . 0 0 9}$ & 0.003 & 0.018 & $\mathbf{0 . 0 2 2}$ \\
$1+\mu$ & 1.500 & norm & 0.5 & $\mathbf{1 . 3 3}$ & 0.91 & 1.76 & $\mathbf{1 . 3 0}$ \\
$1+\nu$ & 1.500 & norm & 0.5 & $\mathbf{4 . 2 0}$ & 3.75 & 4.61 & $\mathbf{3 . 6 0}$ \\
$1+\phi$ & 1.500 & norm & 0.5 & $\mathbf{1 . 0 1}$ & 0.86 & 1.17 & $\mathbf{1 . 0 3}$ \\
$\psi_{F} /\left(1+\psi_{F}\right)$ & 0.500 & beta & 0.2 & $\mathbf{0 . 0 2}$ & 0.01 & 0.04 & $\mathbf{0 . 0 3}$ \\
$\psi_{K g} /\left(1+\psi_{K g}\right)$ & 0.500 & beta & 0.2 & $\mathbf{0 . 2 7}$ & 0.19 & 0.36 & $\mathbf{0 . 2 0}$ \\
$\psi_{K s} /\left(1+\psi_{K s}\right)$ & 0.500 & beta & 0.2 & $\mathbf{0 . 5 1}$ & 0.39 & 0.65 & $\mathbf{0 . 4 7}$ \\
$\psi_{M} /\left(1+\psi_{M}\right)$ & 0.500 & beta & 0.2 & $\mathbf{0 . 0 8}$ & 0.05 & 0.11 & $\mathbf{0 . 0 2}$ \\
$\rho_{g}$ & 0.750 & beta & 0.1 & $\mathbf{0 . 8 3}$ & 0.79 & 0.87 & $\mathbf{0 . 8 6}$ \\
$\rho_{\beta}$ & 0.750 & beta & 0.1 & $\mathbf{0 . 9 7}$ & 0.95 & 0.98 & $\mathbf{0 . 9 3}$ \\
$\rho_{F}$ & 0.750 & beta & 0.1 & $\mathbf{0 . 9 4}$ & 0.91 & 0.97 & $\mathbf{0 . 9 2}$ \\
$\rho_{\gamma}$ & 0.750 & beta & 0.1 & $\mathbf{0 . 8 4}$ & 0.78 & 0.89 & $\mathbf{0 . 8 6}$ \\
$\rho_{M}$ & 0.750 & beta & 0.1 & $\mathbf{0 . 9 5}$ & 0.93 & 0.97 & $\mathbf{0 . 9 4}$ \\
$\rho_{s}$ & 0.750 & beta & 0.1 & $\mathbf{0 . 9 5}$ & 0.92 & 0.97 & $\mathbf{0 . 9 4}$ \\
$\zeta_{K g} /\left(1+\zeta_{K g}\right)$ & 0.500 & beta & 0.2 & $\mathbf{0 . 9 8}$ & 0.96 & 1.00 & $\mathbf{0 . 9 5}$ \\
$\zeta_{K s} /\left(1+\zeta_{K s}\right)$ & 0.500 & beta & 0.2 & $\mathbf{0 . 1 3}$ & 0.06 & 0.20 & $\mathbf{0 . 8 0}$ \\
$\zeta_{M} /\left(1+\zeta_{M}\right)$ & 0.500 & beta & 0.2 & $\mathbf{0 . 2 5}$ & 0.14 & 0.41 & $\mathbf{1 . 5 2 \%}$ \\
$\sigma_{g}$ & & & & & & & $\mathbf{0 . 7 2}$ \\
$\sigma_{\beta}$ & 0.025 & invg & Inf & $\mathbf{1 . 4 9 \%}$ & $1.29 \%$ & $1.70 \%$ & $\mathbf{1 . 4 9 \%}$ \\
$\sigma_{F}$ & 0.025 & invg & Inf & $\mathbf{8 . 9 5 \%}$ & $5.82 \%$ & $13.50 \%$ & $\mathbf{3 . 8 0 \%}$ \\
$\sigma_{\gamma}$ & 0.01 & invg & Inf & $\mathbf{0 . 3 5 \%}$ & $0.27 \%$ & $0.45 \%$ & $\mathbf{0 . 3 3 \%}$ \\
$\sigma_{M}$ & 0.05 & invg & Inf & $\mathbf{6 . 6 8 \%}$ & $5.52 \%$ & $8.06 \%$ & $\mathbf{0 . 6 5 \%}$ \\
$\sigma_{s}$ & 0.025 & invg & Inf & $\mathbf{1 . 3 4 \%}$ & $1.06 \%$ & $1.72 \%$ & $\mathbf{0 . 3 4 \%}$ \\
\hline$\sigma_{s}$ & 0.50 & norm & 0.25 & $\mathbf{0 . 4 9}$ & 0.39 & 0.59 & \\
& & & & & & & $0.86 \%$ \\
\hline
\end{tabular}

Table 11: Prior Distributions and Parameter Estimates of the Model with Usage of Inventories 
Figure 1

Data by Sector.
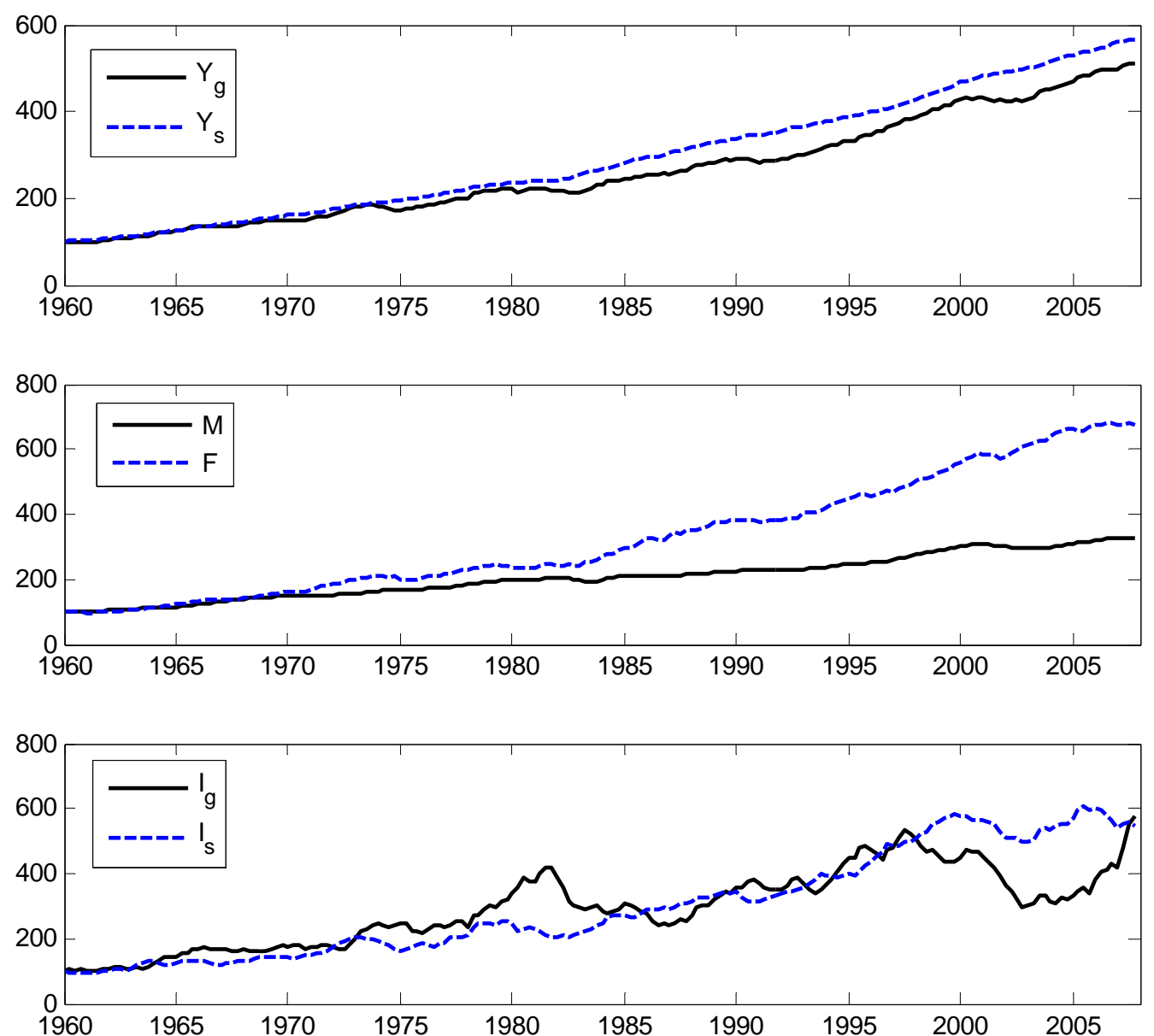

Notes: All series are normalized to 100 in the initial period. 
Figure 2

Nominal Shares of Total Output
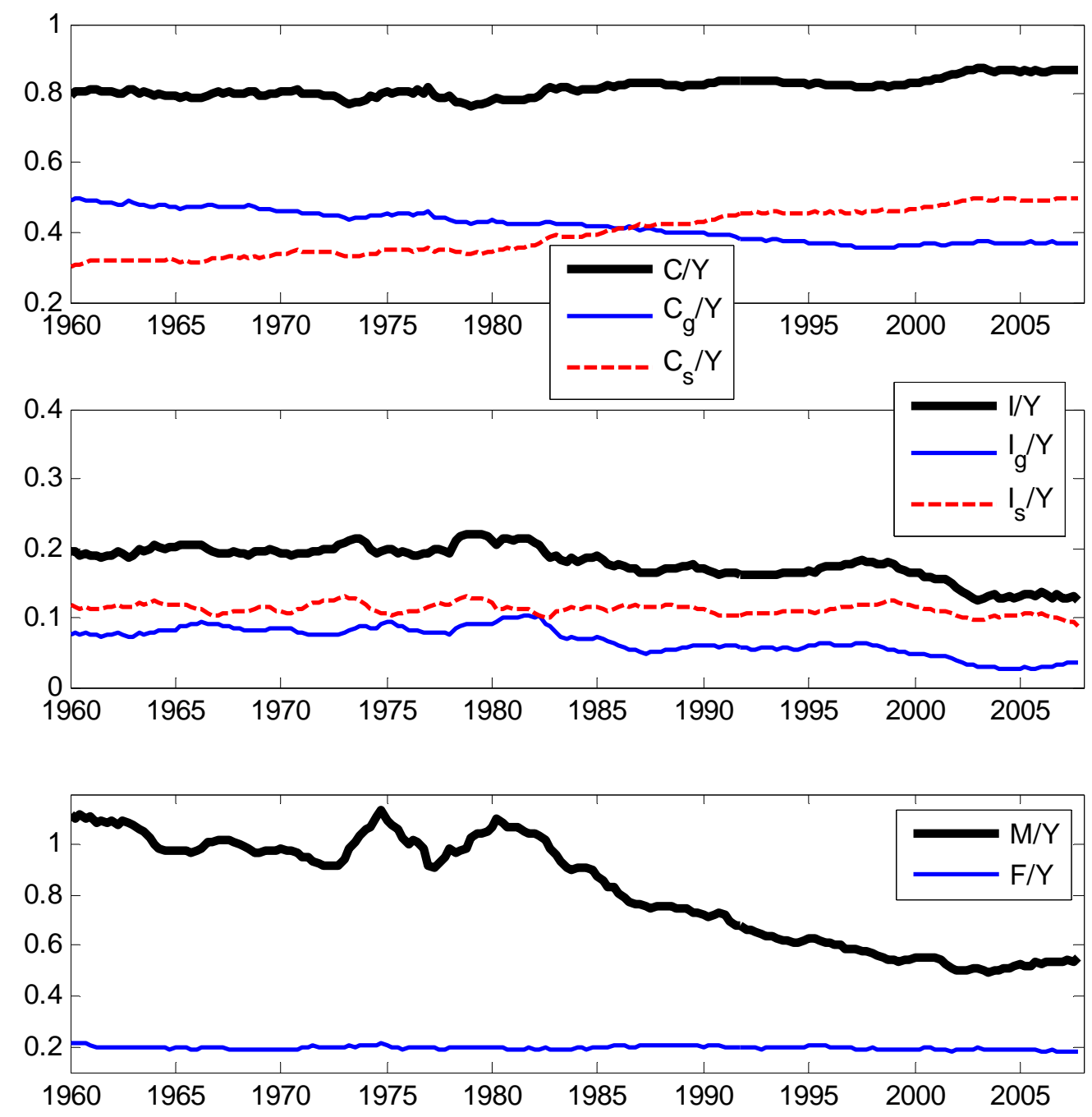

Note: Y denotes total output. Numerators and denominator are all expressed in nominal terms. 
Figure 3

Inventory Target Ratios and Inventory Investment
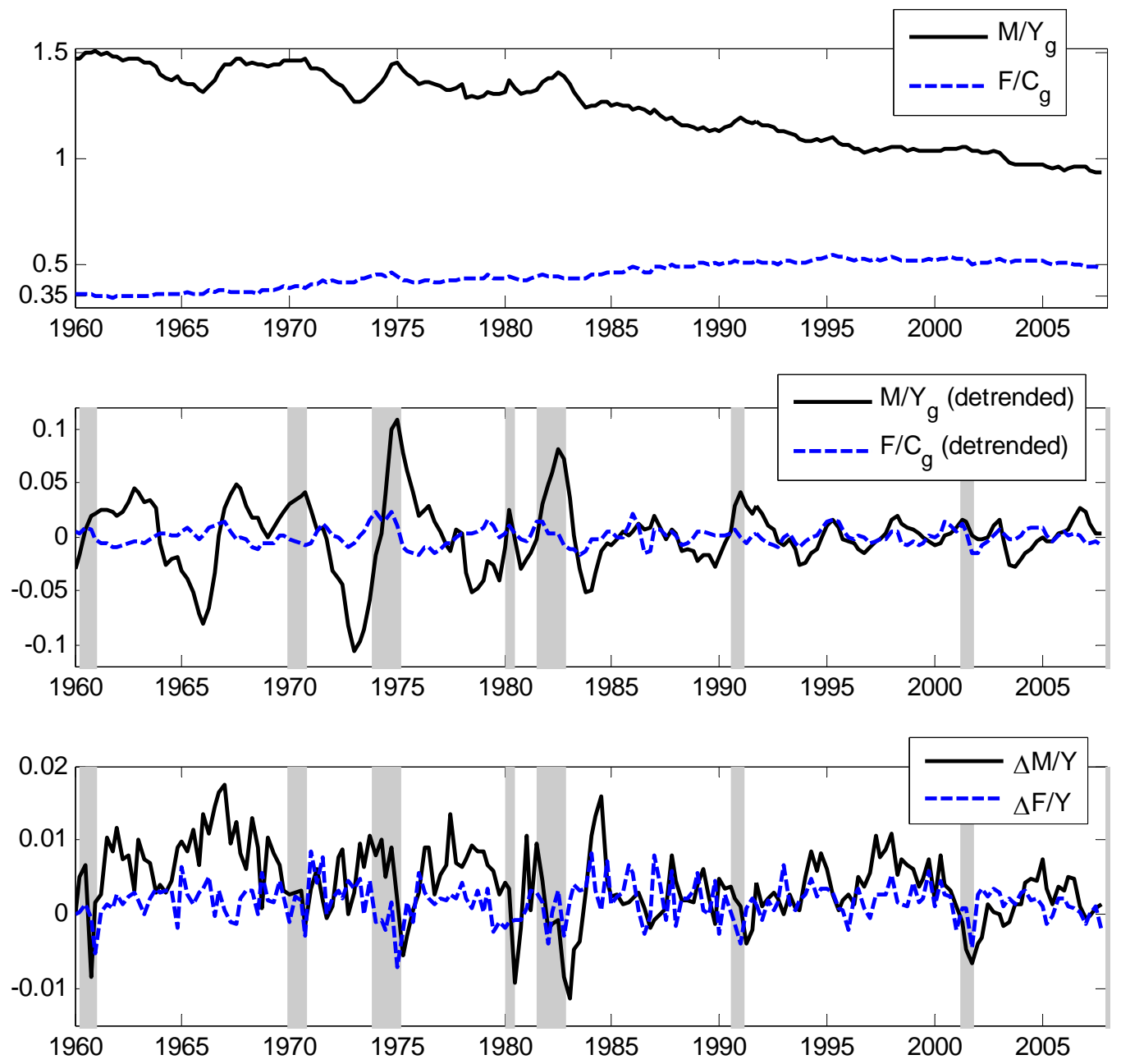

Notes: Shaded Areas Indicate NBER Recession Dates. 
Figure 4

Impulse Responses of the Estimated Model
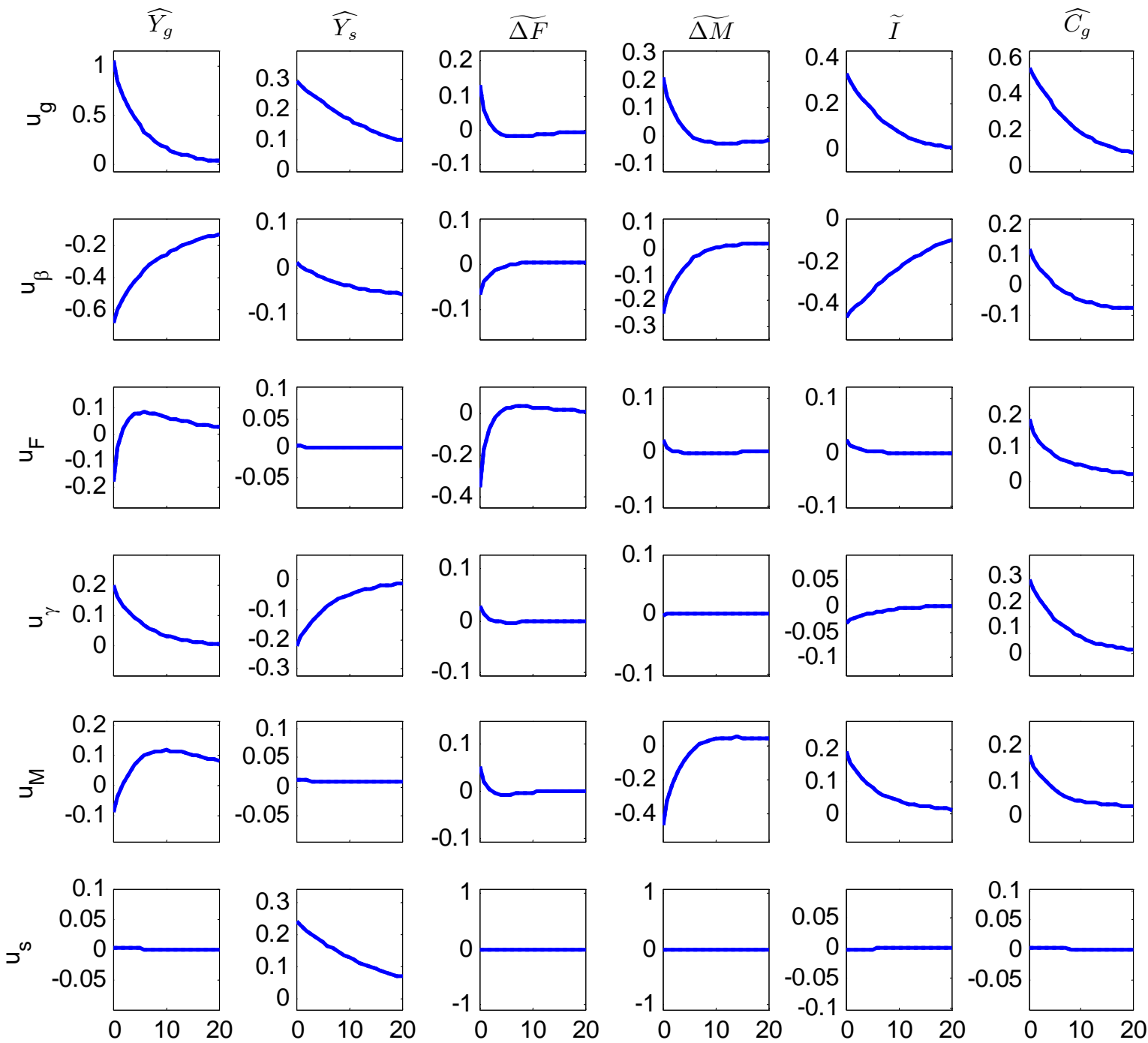

Notes: Each row shows the impulse responses to an estimated one-standard-deviation shock. Xaxis: Time horizon. Y-axis: Deviation from baseline, multiplied by 100 .

Variable with a hat are scaled by their steady state value. Variables with a tilde are scaled by steady state output in the goods sector. 
Figure 5

Impulse Responses of the Estimated Model to Selected Shocks GDP and inventory-to-target ratios
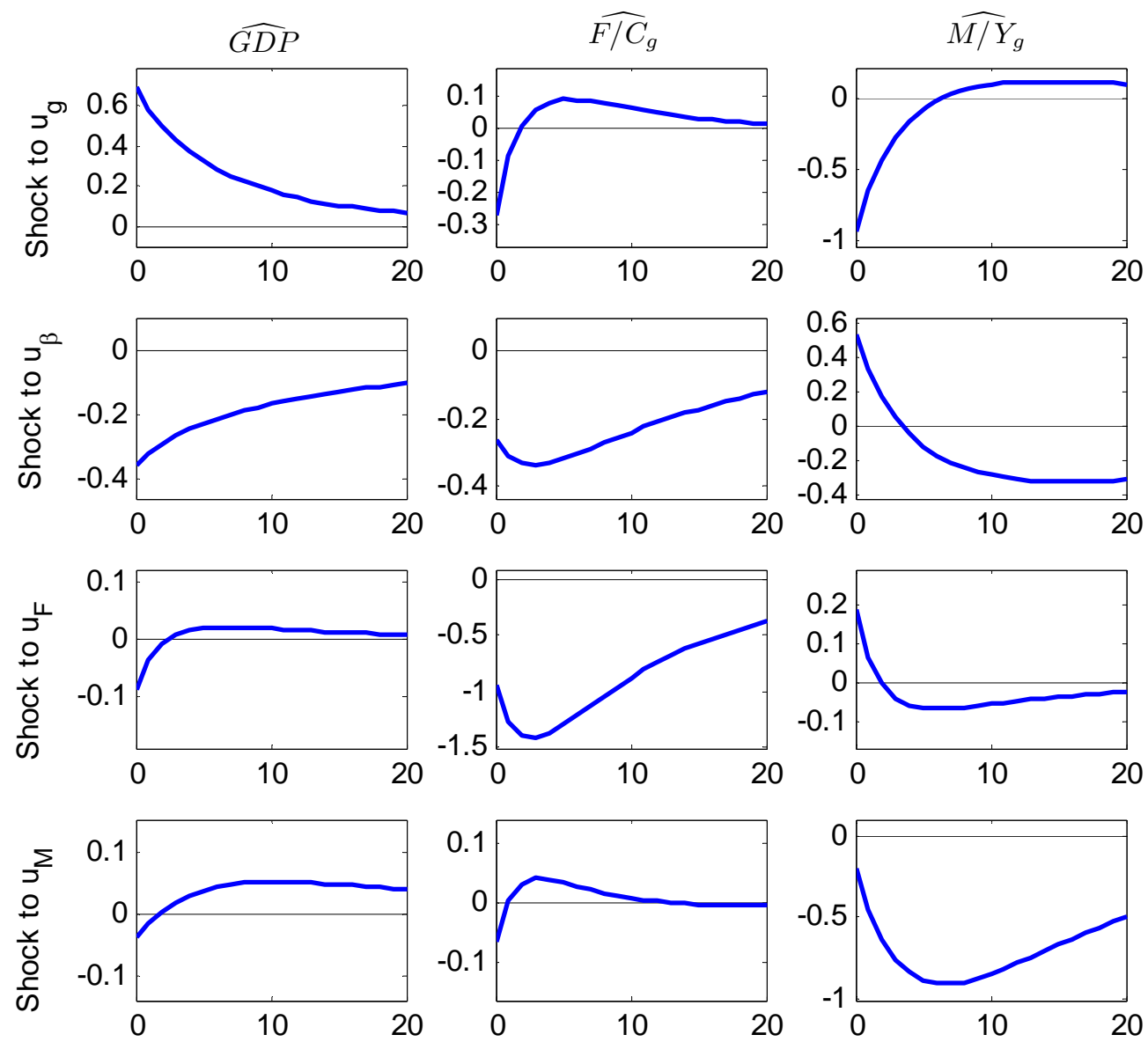

Notes: Each row shows the impulse responses to an estimated one-standard-deviation shock. Xaxis: Time horizon. Y-axis: Deviation from baseline, multiplied by one hundred. 
Figure 6

Orthogonalized Impulse Responses of the Estimated Model, Comparison with VAR.
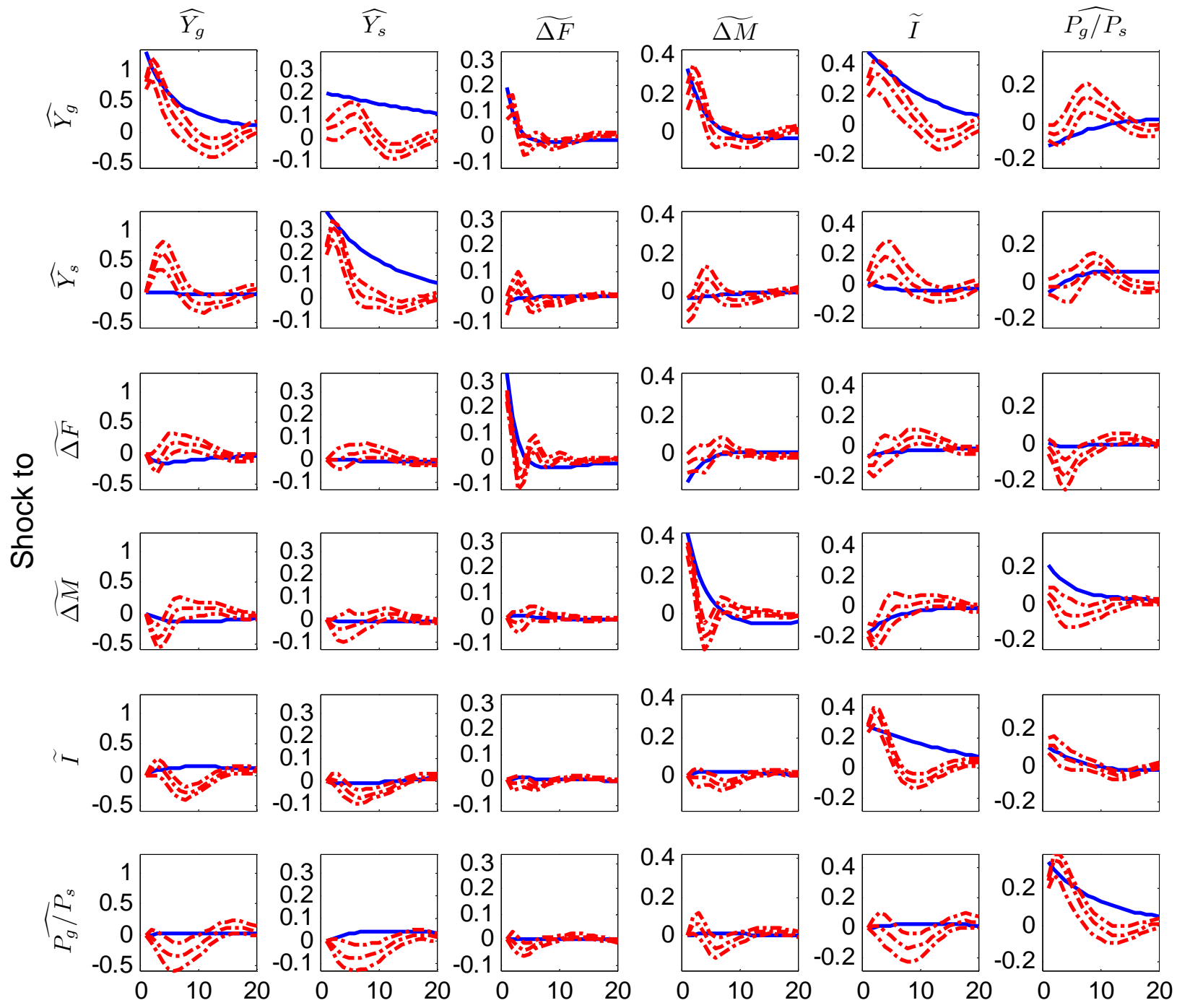

Notes: VAR based on actual data (dashed lines, with two lags and 95\% bootstrapped confidence bands) and VAR based on the reduced form representation of the DSGE model. Each row represents one shock. Both sets of impulse responses have been orthogonalized in the same order. Shocks are one standard deviation. X-axis: Time horizon. Y-axis: Deviation from baseline, multiplied by 100 . Variables with a hat are scaled by their steady-state values. Variables with a tilde are scaled by steady-state output in the goods sector. 
Figure 7

Impulse Responses to a Positive Technology Shock in the Goods Sector
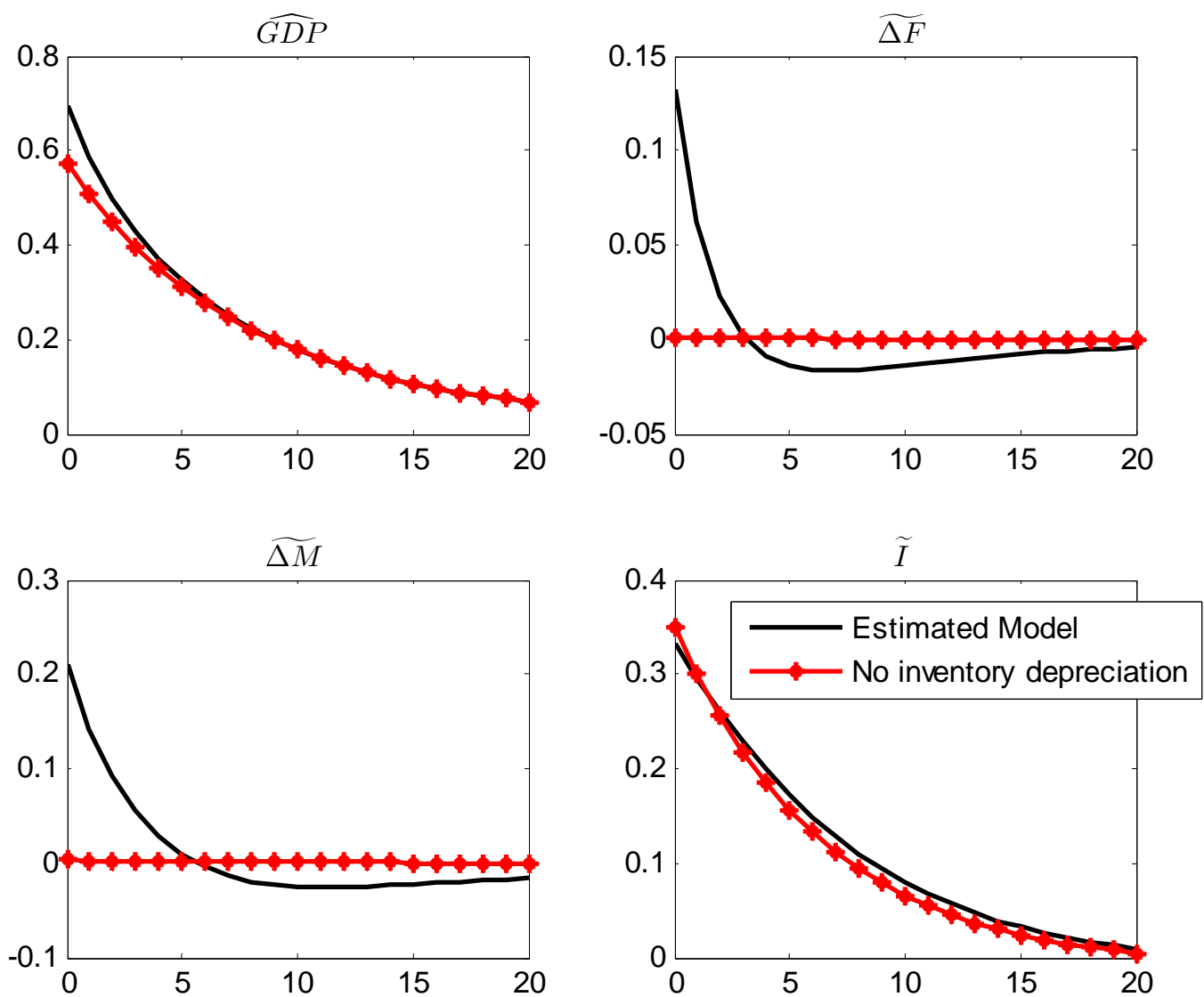

Notes: Responses to an estimated one-standard-deviation technology shock in the goods sector. X-axis: Horizon in quarters. Y-axis: Deviation from baseline, multiplied by 100 .

Output is scaled by its steady-state value. Inventory investment and fixed investment are scaled by steady-state output in the goods sector, so that their impulse responses measure the growth contribution to goods output. 


\section{Figure 8}

Impulse Responses to a Positive Technology Shock in the Goods Sector Baseline Model and Model with Inventory Usage
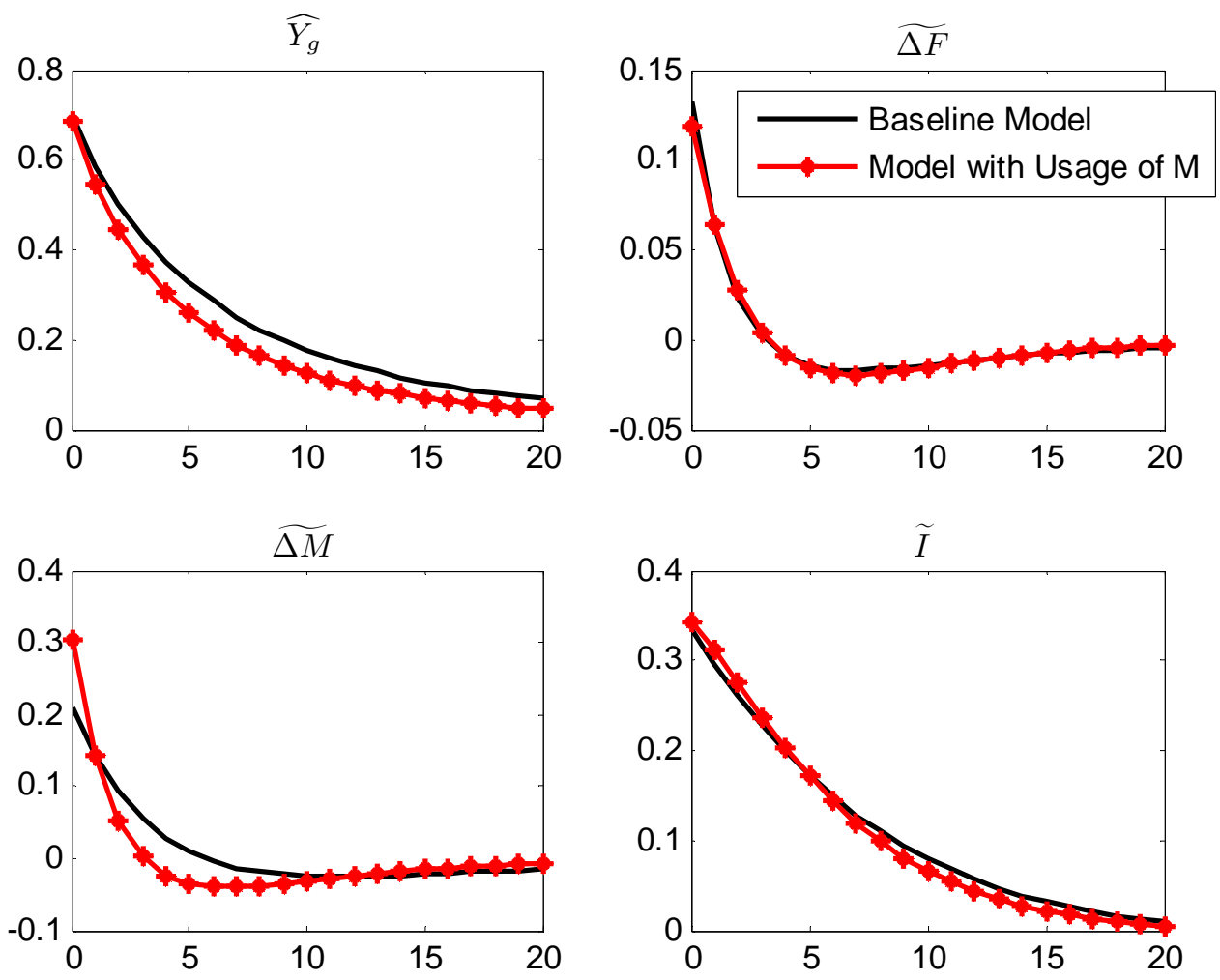

Notes: X-axis: Time horizon. Y-axis: Deviation from baseline, multiplied by one hundred. 